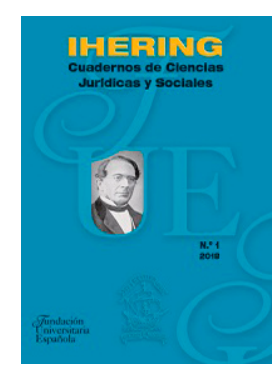

\author{
Ihering. Cuadernos de Ciencias Jurídicas y Sociales \\ $\mathrm{N}^{\mathrm{o}} 1$
}

Año: 2018

e-issn: 2660-552X

DOI: https://doi.org/10.51743/ihering.9

(c) $\underset{\mathrm{EY}}{(1)(9)}$

\title{
Horizonte del liberalismo a la luz del pensamiento político y de España de Ortega.
}

\author{
Claudia Gago Martín \\ Escuela Internacional de Doctorado. Universidad Rey Juan Carlos
}

\section{INTRODUCCIÓN}

'Lo que te preocupa, te esclaviza'

$\mathrm{E}^{\prime}$ 1 trabajo de investigación que se presenta tiene como objetivo estudiar los materiales periodísticos, literarios y filosóficos de José Ortega y Gasset (1883-1955) y María Zambrano (1904-1999) para su contribución a la concepción de un proyecto de país, de un proyecto político que mantiene en ambos casos la tradición liberal como foco de su universo de pensamiento, aunque desde concepciones muy distintas. El fin con el que nace este ensayo es el de acercar al lector a una lectura politológica de los materiales de ambos filósofos, que aunque distanciados en términos generacionales, mantuvieron una relación intelectual brillante fuertemente determinada por la idea de una Zambrano discípula del ya consagrado maestro. Esta relación, forjada entre las letras de la Facultad de Filosofía, sacudida en muchas ocasiones por los avatares políticos que condicionaron ambas vidas y por los enfrentamientos ideológicos de ambos, es la excusa sobre la que iniciar un relato con el que se pretende ahondar en el conocimiento político de los autores y la especial influencia de Ortega en el trabajo de Zambrano. Tal y como indica Ricardo Tejada en su investigación introductoria a la obra de María Zambrano Escritos sobre Ortega: 
El trabajo filosófico de Ortega como el de Zambrano tuvieron una vertiente o faceta intelectual de compromiso social y político con su país, el primero desde la década de los años diez hasta 1932-33, la segunda desde 1928 hasta 1939. Estos periodos de participación cívica, de compromiso ciudadano, se vieron interrumpidos por diversos motivos en los años treinta y no pudieron continuar más tarde (Tejada, 2011: 13).

El estudio se plantea profundizar en los elementos orteguianos que se mantienen presentes en la obra de Zambrano. En concreto, se busca analizar la primera obra de la joven autora, Horizonte del Liberalismo (1930), desde una perspectiva comparada con la conferencia de su maestro, Ortega y Gasset, Vieja y Nueva Política (1914), que influye de forma definitiva muchas de las ideas que maneja y que asienta la base sobre la que Zambrano configura su propio discurso político, filosófico y social. Teniendo en cuenta que ambos textos se publican en el contexto político de la Restauración española (1874-1931), periodo en el que se ubica el régimen militar instaurado por el general Primo de Rivera (1923-1930), dedicamos un segundo apartado al análisis de la posición de ambos autores durante la Dictadura, dado que es el contexto en el que nace Horizonte del liberalismo.

En el intento, ya mencionado, que se persigue, de perfilar ese proyecto de país que defiende cada uno de ellos a través de su obra, se propone en un primer capítulo, "La España liberal de Ortega y Zambrano: Vieja y Nueva Política en el estudio de Horizonte del liberalismo", un estudio comparado entre dos de las obras esenciales de cada uno de ellos para este periodo. En concreto, se realiza una comparación entre la ya citada célebre conferencia de 1914 de Ortega y Gasset, con la que presenta la Liga de Educación Política Española y en la que da cuenta de su visión de regeneración para un país que asume está desintegrado y, por otro lado, la obra de María Zambrano Horizonte del liberalismo.

La selección de las obras responde a que, a pesar de que se publican con 16 años de diferencia, ambas ponen de relieve cómo los autores asumen la supuesta decadencia del país y en nombre del liberalismo proponen una España diversa. Además, la obra de Zambrano fue considerada por el propio autor como en la línea de sus propias concepciones, un símbolo anecdótico que manifiesta las diferencias que entre estas obras se pueden encontrar. 
Como hemos mencionado, a pesar de su carácter original, la presencia de Ortega se mantiene en esta primera obra de Zambrano.

Todo ello aporta el conocimiento necesario para la posterior etapa que asume gran parte de nuestro análisis: la Dictadura de Primo de Rivera. Así, por cuestiones de producción literaria y de posición generacional, Ortega protagoniza nuestro análisis de esos primeros años, mientras la figura de Zambrano asume gran parte del análisis a partir de 1928, marcado por su militancia universitaria. Todo ello lo resumimos bajo un segundo capítulo, "La Dictadura de Primo de Rivera en el pensamiento de Ortega y Zambrano. Intelectuales y acción política”. Esta contextualización a partir del análisis del trabajo periodístico de Ortega durante la etapa inmediatamente anterior a la Dictadura y durante el régimen es esencial para el posterior análisis que se ofrece de la posición política y militante de Zambrano, que vivió la experiencia de la Dictadura desde una posición de juventud en pleno proceso de afirmación de sus primeras reflexiones filosóficas y políticas.

Siguiendo con la línea temporal trazada por Tejada, nos acogemos en este punto del análisis a ese primer periodo de trabajo filosófico, caracterizado por el compromiso social y político, es decir, desde la década de los años 20 hasta 1930. Tomamos como primera referencia algunos de los artículos publicados por Ortega en los años inmediatamente anteriores a la Dictadura, con el objetivo de proponer una suerte de contextualización histórica y política para la mejor comprensión del desarrollo del pensamiento político del maestro. Así, nos adentramos en el universo de Zambrano a partir de los conceptos utilizados por el filósofo.

Además de las cuestiones puramente políticas que se incluyen en esta segunda parte, tales como la trayectoria filosófica de cada uno de los autores, la valoración de la España en la que viven -de la que emiten de forma constante profundos análisis políticos- o la convergencia con otras actividades también de carácter político, social o pedagógico, se ponen de relieve algunas cuestiones importantes acerca de la relación entre intelectual y política, aspecto que se nos antoja relevante para este estudio.

Si bien como dice Ortega en un artículo inédito la palabra intelectual puede irritar, no encontramos otra con la que referirnos a estos autores, por lo que nos acogemos al término para describir a dos escritores que aunaron 
en su obra numerosas disciplinas y que hicieron de la palabra, y de la esencia de ella, su forma de expresar la voluntad de un cambio en su país. Una voluntad transformadora, no obstante, que se presenta muy diferente en cada uno de ellos, pues a pesar de que Zambrano debe gran parte de su pensamiento al de su maestro, lo cierto es que crea un camino propio tanto filosófico como político, en el que las referencias son constantes pero donde hay capacidad para la nueva creación.

La influencia del maestro es tal que Zambrano, ya en 1989, se expresa así con respecto a Ortega:

Ortega fue mi salvación (...) Pero no era su palabra, era su actitud, sin Ortega, aquel momento de España no se hubiera dado. Él tenía la generosidad de escuchar y al mismo tiempo el horror a las tertulias de los cafés, donde tanta cosa maravillosa se decía. Esto le daba no solo una apariencia sino una calidad. En mi discipulaje, por llamarlo de algún modo, con Ortega recibí una revelación en el 'logos del Manzanares' en que las circunstancias están pidiendo ser escuchadas, en que pedían ser miradas sin imponerse -no como se ha entendido después, que hay que adaptarse a las circunstancias- como siervas perdidas que van envueltas en un camino y nadie las reconoce... (Sanz, 1996: 20)

La investigación se centra en estos dos autores, no solo por su estrecha vinculación personal y académica, su contribución a lo político y sus divergencias de parecer, sino porque funcionan en este estudio como representantes de cada una de las generaciones literarias, culturales y políticas que encarnan. Por su parte, Ortega se muestra como el estandarte de la Generación del 14, que comparte con autores tales como Fernando de los Ríos, Manuel Azaña o Eugenio D' Ors (Alzamora, 2014). Una generación hija de la Generación literaria del 98, que se muestra en muchos casos como un hijo rebelde, prueba de ello es la relación de altibajos entre Ortega y Unamuno. Además, es un grupo que acoge el ensayo político como una de sus piezas esenciales, motivo por el que se convierte en fundamental para el propósito que aquí se persigue. Por su parte, María Zambrano encarna el grupo inmediatamente posterior, al que se ha nombrado con numerosos títulos, pero al que nos referimos como Generación del 30 y que de forma casi automática está ligada a la anterior. Esta generación, en concreto María Zambrano, tiene una 
forma muy diversa de vivir la Dictadura, por lo que también nos centramos en la actividad militante de la autora en las asociaciones estudiantiles y en concreto en este punto del análisis en los artículos con los que acompañó esta actividad, la mayoría aquí seleccionados de su columna "Mujeres", en la sección "Aire Libre" del diario El Liberal.

Además, este ensayo se guía por una clara vocación de elevar el mundo de Zambrano al legado orteguiano y de dar una voz femenina al estudio. Se trata de incluir en estas páginas la justicia histórica que se le debe a la autora, negada durante muchos años, aunque recuperada también con una profusa producción posterior en torno a su obra.

Todo el estudio se propone situar a España en el foco de la obra de los autores para contestarnos a la pregunta principal que guía nuestro interés: ¿contribuye el pensamiento filosófico a la acción política y a la construcción de un proyecto político? y, más concretamente, ¿qué posición adopta el liberalismo en los autores de principios de siglo XX?, más específicamente en Ortega y Gasset y María Zambrano ¿y cómo se manifiesta esta tradición política en cada uno de ellos? Con especial atención a la relación intelectual entre ambos. Y de ahí se desprenden otras cuestiones ¿qué importancia tiene la prensa en las primeras décadas del siglo XX en España en la difusión de ideas políticas y como plataforma para la filosofía política, y la literatura?

La metodología escogida para contestar estas preguntas que incluimos es la de una revisión de los textos emitidos por los autores en el periodo aquí expuesto. En concreto nos centramos en los artículos publicados por Ortega en el diario El Sol y aquellos escritos por Zambrano en el diario El Liberal, que será una de las primeras publicaciones que la acoja entre sus páginas -todo ello sin perjuicio de que se incluyan tantos otros-. No obstante, las dos piedras angulares del estudio son la conferencia de Ortega y Gasset Vieja y Nueva Política y el primer libro publicado por Zambrano, Horizonte del liberalismo. Es por ello que recurrimos al estudio comparado para el desarrollo de nuestra investigación, ya que nuestra principal objetivo es el de analizar estas cuestiones en relación a las diferencias que podrían presentar los autores entre ellos y en su forma de concebir un proyecto político óptimo para España.

En este sentido, nuestra intención es dar un sentido literario a toda la sustancia política que se halla en los textos de ambos autores. Nos guía un afán 
por el análisis de los textos que cambian el orden, critican, regeneran, exigen, pero textos que suman en sus postulados la belleza de las palabras bien organizadas, en definitiva, que aportan literatura. En palabras de Zambrano:

El escritor es imprescindible para que aun aquello que en la ciudad ocurra, y clame al cielo, no se quede oculto bajo el silencio opaco, para que salte clamando a los cielos, y si fuera así, el escritor sería el corazón de la ciudad, su centro, el único que podría rescatar a la ciudad de haber sido desposeída de su centro, allanada en verdad (Zambrano, 1985).

Ese escritor que pone en grito la necesidad de un cambio son los aquí escogidos, que situaron la literatura y la filosofía en el centro del debate político y conformaron unas generaciones de escritores preocupados por la cosa pública, preocupados por España, y que la ubican, por lo tanto, en el centro de sus creaciones.

\section{LA ESPAÑA LIBERAL DE ORTEGA Y ZAMBRANO: 'VIEJA Y NUEVA POLÍTICA' EN EL ESTUDIO DE 'HORIZONTE DEL LIBERALISMO'}

'Existo porque pienso y no puedo dejar de pensar'

La investigación que se presenta analiza la implicación política de los intelectuales de principios del siglo XX en España, centrándose en la producción ensayística, periodística, y en tanto que creativa e innovadora, también literaria de José Ortega y Gasset y María Zambrano. Ambos autores mantendrán una relación intelectual objeto de numerosos estudiosos posteriores, en el que la autora se constituye como discípula del filósofo manteniendo, tal y como apunta Carmen Revilla Guzmán, siempre un pulso entre su propia personalidad filosófica e investigadora y los pasos ya dados por su maestro (Guzmán, 2012). Una relación atravesada por numerosos desencuentros y encuentros filosóficos, fuertemente marcada por la admiración de Zambrano al maestro y sus diferencias políticas, más evidentes a partir de 1933 o 1936, siguiendo con el esquema que ofrece Ricardo Tejada en su análisis de la obra Escritos sobre Ortega (Tejada, 2011: 37). 
Como anunciábamos en el capítulo introductorio de este análisis, la idea que guía este epígrafe es la de ofrecer un estudio comparado entre el proyecto para España que se desprende de la lectura de la conferencia de 1914 de Ortega y Gasset, Vieja y Nueva Política, y la primera obra de María Zambrano, publicada en 1930, Horizonte del liberalismo. Ambos textos expresan una forma de concebir el presente y el futuro de España y, teniendo en cuenta el paralelismo y la relación de la producción de Ortega y Zambrano, resulta interesante hacer una comparación de ambos. Esta aproximación a ambas obras sienta la base sobre la que construir un relato en torno a la influencia de Ortega en la obra de Zambrano, que se culmina con un análisis de sus respectivas posturas ante la Dictadura de Primo de Rivera (1923-1930), que completan el objetivo aquí perseguido. De esta forma, el principal propósito que se plantea el capítulo es encontrar, a partir del análisis de Horizonte del liberalismo, a la Zambrano que nace del pensamiento de Ortega, a quien se refiere de forma constante en este momento de su reflexión filosófica y política, y que se ve fuertemente influenciada por la otra obra seleccionada: Vieja y Nueva Política.

En otro orden de cosas, aunque aquí nos refiramos a la literatura como una forma de expresión de valores políticos y sociales esenciales para entender el universo de pensamiento de ambos autores, así como centremos gran parte del estudio en analizar lo que esta producción aportó al debate político y social del momento, lo cierto es que la literatura es una más de las disciplinas que abrazan los intelectuales de estas primeras décadas de siglo XX en nuestro país. Incluso llega a ser la materia denostada y olvidada, en pro de la política o la filosofía. En este sentido, Zambrano se expresa así en una entrevista que rescata Jesús Moreno Sanz en su estudio introductorio a la obra de la autora malagueña Horizonte del liberalismo (1930):

Yo atravesaba entonces, y creo que no he dejado de atravesar, por una situación en que me imponían la necesidad de 'elegir': las personas que me querían me pedían que decidiera entre la literatura, la filosofía o la política. La filosofía me era irrenunciable, pero más irrenunciables me eran la vida, el mundo. Yo no podía (...) apartarme de lo que sucedía en el mundo ni considerarme aparte, ni podía estar sola, desligada, ni podía restringirme a una sola actividad. Porque para mí las tres actividades eran, siendo tres, una y la misma (...), lo que no podía considerarme era 'literata': a la litera- 
tura renuncié en seguida, pero no a la forma, no a la belleza, a la precisión, ni a ese 'qué' ni a ese algo que se encontraba en la literatura (...) (Sanz Moreno, 1996: 31-32).

Es por lo tanto, y en palabras de Zambrano, "irrenunciable" aplicar un criterio literario al análisis de la obra y las cuestiones que aquí se analizan, en tanto que la belleza, la sutileza y el control del lenguaje se convierten en la forma de expresión de los autores, que ante una España que cambia deciden combatirla, desde diversas perspectivas y de forma más manifiesta en el caso de Zambrano, y analizarla. Por otro lado, estas líneas ya dejan entrever la vocación integradora de la autora, que apela a la "unidad", un propósito que acompañamos en esta investigación, que busca decididamente un estudio interdisciplinar entre literatura y política, que sea capaz de exponer materiales literarios y periodísticos al servicio del estudio histórico-político. Cabe señalar que esta premisa es evidente en el estudio de Horizonte del liberalismo que aquí se presenta, por tratarse de un texto que aunque puramente programático, lo cierto es que maneja conceptos cercanos a lo espiritual y lo literario.

El contexto político en el que se encuadran cada una de las obras es diverso, no obstante parece oportuno aclarar que ambos mantienen un tono crítico en sus escritos y mantienen una voluntad de transformar el presente de la España en la que viven. Además se ubican en el proceso histórico político de la historia de España al que nos referimos como Restauración y que tan presente está en la obra de nuestros autores, y al que, por tanto, nos referiremos de forma constante en el estudio.

Siguiendo el estudio de Ramón Villares y Javier Moreno Luzón en Restauración y Dictadura, la Restauración es aquel momento monárquico que se sucedió en España entre ambas repúblicas, una, iniciada en 1873, otra, la Segunda República, proclamada en 1931. El proceso intermedio al que nos referimos, en palabras de los autores, "comenzó siendo un salvoconducto para la estabilidad, la prevención del virus revolucionario y la consiguiente salvaguarda del orden social, y terminó ahogada por el golpe del general Primo de Rivera" (Villares y Moreno Luzón, 2009: 15). Este régimen constituido como una monarquía constitucional, bajo la figura de Alfonso XII, que ha pasado a la historia por un periodo de estabilidad política, se asentó sobre la base del turnismo entre el Partido Liberal Conservador de Cánovas del 
Castillo y el Partido Liberal de Sagasta (2009: 14), siguiendo con lo expuesto por los autores esta experiencia de gobierno se define por "la existencia de dos partidos monárquicos que se alternaban pacíficamente en el poder" (2009: 413). En palabras de Javier Zamora Bonilla en su biografía de Ortega y Gasset, respecto al turnismo y al proceso electoral de la España del momento: "Las elecciones eran una farsa en la España de la Restauración. Una sociedad nada politizada se abandonaba al juego de favores que representaba el caciquismo [...] Cuando el caciquismo no funcionaba se recurría descaradamente a la manipulación electoral" (Zamora, 2002: 27).

Tal y como avanza el título del capítulo "La España liberal...", la tradición política que inspira el pensamiento de María Zambrano y de José Ortega y Gasset en las obras aquí presentadas es el liberalismo, que acogen desde perspectivas diversas, transformándolo en proyectos diferentes para España. Ambas obras, publicadas durante la primera mitad del siglo XX, se enmarcan en un contexto en el que en Europa se gestaba desde finales del siglo XIX la idea del Nuevo Liberalismo, que tan presente está en la obra de ambos autores, como se estudiará más adelante.

El Nuevo Liberalismo surge de una necesidad de regenerar el liberalismo imperante hasta el momento, como una corriente del liberalismo social. Así, se caracteriza por desprenderse del individualismo propio del liberalismo clásico, para asumir al individuo como parte de la sociedad, cuya actividad afecta de forma definitiva a esta -muy presente en la obra de Zambrano-. Uno de los principales teóricos de esta corriente de pensamiento, el británico Leonard Trelawny Hobhouse (1864-1929) incluye en su obra Liberalism la idea de que la institución por la que se regía el antiguo liberalismo es el individuo (Hobhouse, 1911: 24).

El Nuevo Liberalismo, además, tiene una relación directa con la idea de democracia, a la que se apela en las obras aquí seleccionadas como se analizará posteriormente. Hobhouse lo explica así:

Democracy is not founded merely on the right or the private interest of the individual. This is only one side of the shield. It is founded equally on the function of the individual as a member of the community. It founds the common good upon the common will, in forming which it bids every grown-up, intelligent person to take a part (Hobhouse, 1911: 97). 
De esta afirmación, se deduce por lo tanto, la existencia de un bien común, determinante para entender ese nuevo concepto de comunidad que va más allá de los intereses individuales. Junto a esta idea, el Nuevo Liberalismo incluye una revisión del Imperialismo, que considera su principal enemigo. El escritor, representante de estas ideas, que se desarrollarán sobre todo en Inglaterra, explica con más profundidad este concepto y se expresa contundente al afirmar que el liberalismo se encuentra en conflicto con la idea clásica de Imperio, al considerar que los imperios coloniales son la gran creación del antiguo liberalismo (Hobhouse, 1911: 102).

En España este Nuevo Liberalismo dará lugar a profundos debates entre los pensadores del momento. No solo se trata de que estas ideas, venidas desde Europa, tiñan las obras que aquí se estudian, motivo por el que las presentamos de cara a facilitar la lectura de la investigación, sino que se convirtieron en materia de discusión en el contexto intelectual de la España de principios del siglo XX, como es el caso del propio Ortega.

En este sentido, y a modo de introducción a algunas de las ideas que Ortega desarrolla en Vieja y Nueva Política que analizaremos en el capítulo y que determinan parte del pensamiento de Zambrano, en 1908 Ortega publica en el primer ejemplar del semanario Faro un artículo titulado "La Reforma Liberal", en el que arremete contra la clase política española, incapaz de crear un proyecto liberal que represente las necesidades de la sociedad española de entonces. En este momento, además, el artículo se tiñe de un tono pesimista, algo constante en esta primera etapa de los autores de la Generación del 14, que son herederos de un siglo XIX "escasa de cuadros tecnocráticos capaces de revolucionar las condiciones materiales, para, abordar las morales y las políticas" (Alzamora, 2004: 78), en lo que ahondaremos en el estudio. En este mismo sentido se expresa Ortega en este artículo de 1908, en el que observa la necesidad de los líderes para encarnar las ideas políticas, algo que no sucede en España: "Para ello es menester que resucitemos el liberalismo y que luego el liberalismo instaure con sus manos sabias y puras un verdadero partido liberal" (Ortega y Gasset, 2004: 142) en clara referencia al Partido Liberal de Sagasta, cuyo fallecimiento en 1903 había conducido a un periodo de crisis en el partido, que se debatía entre varias corrientes sin que ninguna llegara a imponerse (Zamora, 2002: 69). 
Hemos convenido en detenernos en este artículo porque sugiere varias líneas imprescindibles en el pensamiento de Ortega que estarán presentes en Vieja y Nueva Política, tanto es así que en estas líneas el autor explica de forma contundente el liberalismo que propugna y defiende, y que posteriormente le llevará a la conformación de la Liga de Educación Política, ante la observancia de una falta de liberalismo real en España y la frustración en torno a la oferta política española, según el autor protagonizada por un conservadurismo insuficiente e ineficaz. En este sentido, nos remetimos a las palabras de Ortega, que explica brevemente el liberalismo en el que cree:

Llamo liberalismo a aquel pensamiento político que antepone la realización del ideal moral á cuanto exija la utilidad de una porción humana, sea ésta una casta, una clase ó una nación. La dirección conservadora, por el contrario, se desentiende de ideales, niega su valor ético y se atiene en este punto a lo ya logrado, cuando no fomenta el regreso a formas superadas de constitución política (Ortega y Gasset, 2004: 143).

Este artículo es símbolo de esa influencia europea del Nuevo liberalismo, que llevó, como explica Zamora en la biografía del filósofo, un profundo debate político con Gabriel Maura, hijo del presidente del Gobierno en ese momento, el conservador Antonio Maura, y figura decisiva del Partido Conservador, que recriminaba el utopismo de la reforma liberal en pro de una reforma conservadora. Para el joven Ortega el conservadurismo "no es una idea, es un instinto" (2002: 69), y por lo tanto lo rechazaba, por su incapacidad de generar cambio.

A esta idea de un liberalismo elevado, ético y moral, se le une el término "revolución", pues en este punto de la vida del joven Ortega -apenas cuenta 25 años en el momento de publicar este artículo-, confía en la existencia de un liberalismo como "sistema de revolución", necesario si no se quiere matar a la idea y hacerla desaparecer en la Historia. Se expresa así para aclarar este punto: "Un sistema es una idea: sistema de la revolución significa, pues, idea de la revolución o revolución ideal". Tal y como expone Marichal, no obstante, Ortega no se refiere en ningún momento a la idea revolucionaria violenta, simplemente a la variación del orden constitucional. Cabe mencionar, además, que nos encontramos ante un Ortega deslumbrado por el socialismo, 
en concreto con el Partido Socialista Obrero Español que considera una fuerza electoral en auge. Ello le conduce a observar necesaria la convergencia entre partido político de tradición liberal y el socialismo, desprendiéndose esta última corriente de su concepción de clase. Es así como nace su proyecto de Partido Liberal Socialista -que nunca llegó a existir y para el que quiso contar con Unamuno-. Esta confianza en el socialismo se entiende por el carácter europeísta del autor, en concreto su conexión con Alemania -donde estudió-, y donde en este momento el partido socialista estaban en auge. Así, el joven Ortega confía en el carácter europeizante del socialismo (Marichal, 1990), del que dice que es "cultura".

A partir de este momento y en los años sucesivos, la cultura se convierte en Ortega en la esencia de la salvación de una nación española débil. La cultura es el instrumento de superación y elevación de la tradición cultural heredada. Téngase en cuenta que nos encontramos ante un Ortega que desarrolla intensamente, hasta la publicación en 1914 de su obra Meditaciones del Quijote, una revisión muy amarga y pesimista de la historia de nuestro país, y en la que el autor encuentra gran parte de las patologías que nos acompañan (Alzamora, 2014), algo que Manuel Menéndez Alzamora resume de forma gráfica al afirmar que "Ortega contempla con un poso amargo la historia de su pueblo" y que da cuenta de las sensaciones que acompañan al autor en esta etapa. Como bien sentencia Alzamora respecto al Ortega del 14: "El punto de partida es lo que somos en cuanto lo que hemos sido". Todo ello, que nos sitúa ante las ideas del joven Ortega y sirve como antesala al estudio que se ha introducido, quedará manifiesto en su conferencia en el Teatro de la Comedia en marzo de 1914 con su discurso Vieja y Nueva Política.

La conferencia Vieja y Nueva Política aparece en este contexto político, tan solo dos meses después de las elecciones generales de 1914, en las que el Partido Conservador se hace con el Gobierno, dirigido por Eduardo Dato. En la esfera europea todavía no se ha iniciado el conflicto internacional, que no tardará en llegar, pero sin duda nos encontramos ante un escenario de tensión y ruptura. No obstante, este discurso es el resultado de la reflexión durante años del filósofo, que ya manifestó algunas de las ideas que en él se exponen a través de otros artículos ante- 
riores -como el aquí expuesto- que sigue desarrollando en publicaciones posteriores, que analizaremos en el capítulo siguiente. Además, la importancia de este momento - de este año- da nombre a la generación que lidera Ortega, a la que nos hemos referido como Generación del 14 y que ha llevado a sentenciar que el año 14 fue un año de fractura.

El motivo de la conferencia es la presentación de la Liga de Educación Política Española, una institución que nace después de la agrupación Joven España -de 1910-, a la que ya había pertenecido Ortega junto a otros escritores como Fernando de los Ríos, Ramón Pérez de Ayala, Augusto Barcia, etc. (Alzamora, 2014: 107). Joven España es una agrupación de jóvenes que conformaban el sustrato intelectual de la España de principios de siglo, que mantiene una clara vocación renovadora, pero acabará desintegrándose ese mismo año. En palabras de Tomás Álvarez Ángulo miembro del Comité central ejecutivo de Joven España-, rescatadas por Menéndez Alzamora en su estudio, describe el grupo así: "Se trataba de formar una especie de liga de los derechos del hombre, un conjunto de inteligencias brillantes para difundir por doquier los progresos de las teorías revolucionarias. ¿Procedimiento? Conferencias, hojas volanderas, folletos". Así se constituye como una plataforma desde la que combatir el, en su opinión, fracaso de la Restauración, por lo que podemos reiterar su carácter transformador (2014: 107) Ya en 1913 se constituye la Liga de Educación Política, con pretensiones similares y cuyos miembros a menudo coinciden. De forma anexa a la Liga, en esta primera década del siglo XX y los años inmediatamente posteriores, comienzan a surgir una serie de instituciones para velar por la cultura española que servirán de abrigo para poner en escena a estos autores (Alzamora, 2014: 87), ejemplo de ello es la Residencia de Estudiantes (1910), que tal y como apunta Menéndez Alzamora en su estudio sobre la Generación del 14, rescatando la Exposición de motivos del Real Decreto del 6 de mayo de 1910, tenía una clara vocación de servir como un espacio que fomentara "la fraternidad y el estudio". En definitiva, tenía intención de crear una institución intelectual que abrazara el nacimiento de una generación (2014: 83) y que, finalmente, sirvió de plataforma para estos autores del $14 \mathrm{y}$, por supuesto, determinó el surgir del venidero grupo poético del 27. Junto a la 
Residencia de Estudiantes, otra de las grandes instituciones para la cultura y el saber fue la Junta para Ampliación de Estudios e Investigaciones Científicas (1907-1939).

Con la guerra internacional ya iniciada en julio de 2014, en España se produce, en los años sucesivos, un profundo debate entre germanófilos y aliadófilos, las dos únicas opciones que se contemplaban en el país y que acaparan el discurso público del momento. "La germanófila -explican Villares y Moreno Luzón en su estudio- se trataba de una neutralidad a ultranza que, al perjudicar a los aliados -más próximos-favoreciese a los alemanes; y la aliadófila, una benevolencia hacia la entente que, en caso de tensiones extremas, pudiera desencadenar en la intervención efectiva en la guerra" (2009: 427). Dato, que mantuvo siempre la neutralidad de España, fue, en 1915, sustituido por el conde de Romanones, aliadófilo y de los pocos que defendió la entrada en la guerra (Zamora, 2002: 151).

Frente a este panorama en el que Ortega hace pública su conferencia Vieja y Nueva Política, la obra de Zambrano se publica en 1930, en seguida de la caída de la Dictadura de Primo de Rivera y después de que la autora hubiera participado intensamente, como analizaremos el capítulo siguiente, en el activismo universitario contra el régimen. Por lo tanto, la obra aquí seleccionada para el estudio serviría como conclusión de esas ideas y plantea de forma profunda su visión de la España del momento, de la función de la política y reitera su criterio de unidad por el que debe guiarse, en conjunción con la poesía, la filosofía o el amor.

Así, en primer lugar ambos textos exponen su necesidad de convertirse en un escrito político y se presentan como un texto programático. Es decir, se percibe que los autores presentan un texto puramente político, acompañado de tantas otras materias, pero cuya razón de ser se encuentra en un análisis de la realidad y en una concepción regeneradora de la misma.

En este sentido, Ortega es claro en su discurso Vieja y Nueva Política, cuando aclara su condición de "intruso" en la política, pero su evidente intención de intervenir en el debate público: "Harto conozco no ser uso en nuestro país que a quien no ha entrado en un cierto gremio formado por gentes que ejercen un equívoco oficio bajo el nombre de políticos se le repute como un normal derecho venir a hablar en público de los grandes temas na- 
cionales" (Ortega y Gasset, 2004: 709), comienza Ortega su intervención. En este mismo sentido, Zambrano presenta su obra con un epígrafe dedicado a la política e identifica la misma con el valor de la reforma. La política no es poder, el poder es el instrumento para la reforma, y a partir de esa afirmación se inicia el camino por una obra de corte reformista, reflexiva, intimista y cercana a lo poético, todo ello con una clara intención de intervenir en el discurso político: "Hay una actitud política ante la vida, que es simplemente intervenir en ella con un afán o voluntad de reforma. Se hace política siempre que se piensa en dirigir la vida" (Zambrano, 1996: 203). Zambrano siempre mostró su voluntad de reforma, de dirigir la vida, por lo que según sus palabras, la guía una fuerte vocación política.

Aclarado, por lo tanto, que nos hallamos ante el estudio de textos producto de reflexión de años y con una intención transformadora y puramente guiada por valores políticos, nos iniciamos en la tarea de descubrir algunos de los conceptos básicos que presentan y que sirven para entender el contexto histórico-político de la España de las primeras décadas del siglo XX.

En el sentido de lo expuesto, Ortega presenta ya en este momento parte de la teoría de las masas y las minorías que seguirá desarrollando más profundamente con el paso de los años. En este punto, el autor considera imprescindible para la vida política la participación de los intelectuales -algo que le produce ciertas contradicciones en algunos momentos de su vida- por lo que llama a unas minorías "más cultas, más reflexivas, más responsables" para que colaboren en la transmisión del pensamiento político a esas masas o "pobres grandes muchedumbres dolientes". Es un texto, por lo tanto, dirigido a esas minorías, como así lo aclara:

Los programas usaderos son caducos e inútiles -venid a trabajar a un nuevo edificio de ideas y pasiones políticas-. Yo ahora no pido votos; yo ahora no hablo a las masas; me dirijo a los nuevos hombres privilegiados de la injusta sociedad -a los médicos e ingenieros, profesores y comerciantes, industriales y técnicos-; me dirijo a ellos y les pido su colaboración (Ortega y Gasset, 2004: 725 )

La influencia de Ortega en Zambrano es evidente, ya sea para desligarse de sus concepciones, como para acogerse a ellas. Tanto es así, que la autora 
recurre al concepto acuñado por Ortega de "hombre masa" en parte de su estudio, en concreto para afirmar que no es a esas gentes a las que llega la moral liberal, sino que en su esencia ha sido un mensaje destinado a "minoría, gentes cultivadas, intelectuales", que dará pie al inicio de la reflexión de la autora acerca de una reforma del liberalismo (Zambrano, 1996: 241)

Otra idea fundamental que se deduce de las palabras que incluimos de Ortega es el dolor, que menciona al referirse a la muchedumbre y que forma parte del discurso del filósofo, que reconoce que España le duele. Precisamente de ese dolor nace la Liga que se presenta a través de estas palabras, en un contexto en el que España ha vivido el desastre de 1898 -al que se refiere- y del que a fecha de 1914 no ha sido capaz de superar. Este tono pesimista que da inicio a la lectura del país de Ortega y que matiza a lo largo de la conferencia, es diferente al que Zambrano emplea para su obra, teñido de un optimismo casi espiritual y de fe en el ser humano -las referencias religiosas son constantes- y en su capacidad para crear un nuevo país. Además, la autora considera que el pesimismo es una posición doctrinal propia de las políticas conservadoras, pues "toda teoría vital de matiz pesimista niega de por sí cualquier cambio político" y por ello reflexionará sobre la necesidad de una política revolucionaria (Zambrano, 1996: 218). Así, ella considera que nos encontramos en un momento de ruptura, un momento de contradicción que da la oportunidad de gestar algo nuevo. Tejada, en su análisis de la obra Escritos sobre Ortega, lo resume así:

Horizonte del liberalismo apunta hacia una especie de vitalismo espiritualista, teñido de espíritu revolucionario, de difícil acomodo con la realidad política de la época, y hacia una apertura humanizadora, social y popular del liberalismo, bastante alejado de los presupuestos orteguianos. Hay algo utópico en este liberalismo vitalista, lo que le acerca a posicionamientos que defenderá posteriormente Eugenio Imaz, y muy poco de marxismo, aunque en algunos puntos puedan ir de la mano (Tejada, 2011: 35).

Esa referencia que hace Tejada a la lejanía que encontramos entre las obras de los autores fue materia de debate en el momento de la publicación. El libro de Zambrano fue acogido como profundamente anti-orteguiano, algo que la autora intentó justificar o explicar al maestro, tal y como señala Tejada, haciéndole llegar su sentimiento de "discípula" y recordándole que mu- 
chas personas que lo habían leído observaban en él una fuerte influencia del maestro (Tejada, 2011: 36). Una influencia que se verá sobre todo en el peso de la Historia en su análisis o en su reflexión sobre la razón como un eje central del estudio, que analizaremos a lo largo del capítulo.

No obstante, cabe matizar que a pesar de los ojos pesimistas con los que Ortega observa la España que le rodea no le conduce a sentenciar su fin, sino que ya la simple implicación en un proyecto político -como era la Liga-, aunque no fuera un proyecto político al uso, indica una voluntad y una confianza en la posibilidad de superación. Algo que aclara cuando dice: "No nos sentimos de temperamento fatalista: al contrario, pensamos que los pueblos renacen y se constituyen cuando tienen de ello la indómita voluntad. Todavía más: cuando una parte del pueblo se niega reciamente a fenecer".

Así las cosas, Zambrano, por su parte, reflexiona en su obra sobre política y liberalismo. En ese proceso ofrece una reflexión sobre la política conservadora y revolucionaria, y considera el proceso político de la Restauración un proceso profundamente conservador y rígido. "Rigidez -en sus palabrasmás terrible, porque se halla justificada, exaltada y se la considera no ya un mundo, sino el mejor -el único- de los mundos" (Zambrano, 1996: 211). Cabe decir que el proceso de la Restauración y la posterior dictadura militar son el caldo de cultivo sobre el que reflexiona la autora, así como el propio Ortega, que dedica parte de su intervención a una reflexión sobre la Restauración. Por su parte, el maestro apela en 1914 al fin de la crisis de la Restauración, a la que considera "la detención de la vida nacional", que vendría a confirmar la visión conservadora de Zambrano y que el autor relaciona con la falta de dinamismo en la nación española en ese momento, advirtiendo: "Cuando nuestra nación deja de ser dinámica cae de golpe en un hondísimo letargo y no ejerce más función vital que la de soñar que vive" (Ortega y Gasset, 2004: 720). Además, Ortega considera que la falta de dinamismo y de evolución que acompaña la Restauración se ha utilizado bajo la falsa necesidad de imponer el "orden público", y a partir de ese pretexto se evita atacar los problemas fundamentales del país - que Ortega relaciona con la raza y la nación-. Además, el autor identifica la Restauración con un esquema de "convencionalismo y simplismo". 
En palabras de Moreno Luzón y Villares, que bien nos ayudan a entender a Ortega en este momento y sintetizan lo ya expuesto, en Vieja y Nueva Politica, el filósofo "abominaba de la Restauración, una fantasmagoría tejida por Cánovas sin sustancia alguna y en pleno declive, decrépitos ya los capitostes del turno y a la espera de la completa renovación -en sentido liberal y democrático- la monarquía" (Villares y Moreno Luzón, 2009: 418).

Este proyecto político que inicia Ortega y que acaba de presentarse, La Liga, tendrá una profunda afinidad con el Partido Reformista, creado un año antes por Melquiades Álvarez y Gumersindo de Azcárate, tanto es así que Ortega ingresa en el partido y junto a Luis de Zulueta y Manuel Azaña entre otros, fueron miembros de su junta nacional. Sin embargo, esa buena sintonía empezará a desquebrajarse en el momento en el que Melquiades Álvarez inicia una aproximación hacia el Partido Liberal, que Ortega consideraba un elemento improductivo de la política española, propio de la Vieja política a la que apela en su discurso y por la que era imposible que pasara la regeneración del país. A ello se le suma la actitud adoptada en el contexto de la Primera Guerra Mundial por Melquiades Álvarez, que abogaba por continuar los pasos de Inglaterra, una sumisión que hería las pretensiones de Ortega. No obstante, la relación no se fractura (Zamora, 2002: 154-155).

La idea orteguiana que se mantiene a lo largo de la conferencia es la importancia de la Historia como un factor explicativo del devenir político y social del país, y que se desarrolla en obras posteriores como Meditaciones del Quijote, que se publica ese mismo año. Este historicismo patente en Ortega se encuentra en parte de los conceptos con los que trabaja Zambrano en su obra. Aunque la autora bebe del maestro el gusto por encontrar razones históricas y acudir a esa fuente de conocimiento para sus valoraciones políticas, Zambrano acoge y reforma esos conceptos.

Ortega presenta ya en 1914 un discurso influenciado por un fuerte determinismo histórico, no tan presente en la obra de Zambrano. Tanto es así que acaba por declararse monárquico "no porque hagamos refiriéndose a la Liga- hincapié en serlo, sino porque ella, España, lo es", es decir, España manifiesta un componente propio que la hace monárquica, la Historia. Ello también le conduce a hallar el problema de España en un problema histórico de la raza, donde lo fracasado no son hombres o 
instituciones concretas, sino el haber demostrado históricamente un desapego a los principios del pueblo.

En este sentido, María Zambrano aporta nuevos conceptos en relación con la influencia de la historia en el pensamiento político, y asocia el conservadurismo histórico al estatismo político. El conservadurismo histórico y cognoscitivo son términos que Zambrano emplea para identificar la idea que se ha insertado en parte del imaginario colectivo de que el mundo y la vida ya están creados, y, por lo tanto, no hay nada por llegar, nada nuevo que ofrecer, algo que afecta necesariamente al surgimiento de una nueva política -en términos orteguianos-. Se expresa así: "Conservadurismo histórico, estatismo histórico. Nada nuevo es posible; cualquier forma es desorden, pecado, degradación. Y de aquí, naturalmente, una paralización absoluta de los principios que rigen la vida política" (Zambrano, 1996: 216). Es decir, la autora concede importancia sustancial a la historia, pero apela a que esta podría ser, depende de cómo sea interpretada, una fuerza limitadora para cambios necesarios.

Este marcado historicismo se desarrolla intensamente en toda la producción filosófica y literaria de los autores. Así, Zambrano declara en su reflexión del liberalismo: "Y en la historia, cada época tiene los suyos [supuestos] que sólo la lejanía, por contraste, permite percibir; y en consecuencia, la política". Es decir, atribuye a la historia un papel definitivo en la percepción de la política. Además, observa que nada muere, ninguna idea, pues "deja su jugo a la Historia" (1996: 227). La Historia es, en palabras de Zambrano "grave teoría de acaeceres y sucesos que pasan y quedan, porque se enlazan con otros". Desde esta concepción, su idea es responder a cuál será el poso de liberalismo en España, en un momento que se predice que ha llegado a su fin.

Además de esta influencia de Ortega en la presencia de la Historia, Zambrano hereda su gusto por el racionalismo, algo que puede considerarse como una condición que le acerca y le aleja del maestro, pues en Horizonte del liberalismo, la autora admite su admiración a la razón, pero sin duda la mayor parte de su pensamiento gira en torno a una reforma de la misma, la integración del sentimiento, de la vida, de la pasión, en definitiva, de la irracionalidad -aunque no así caer en el irracionalismo-, en 
la reflexión política; algo que acusa al liberalismo racionalista de haber ignorado. Así, se pregunta: "El retorno a la fe [...], el reconocimiento de la legitimidad del instinto, de la pasión, de lo irracional, ¿no podrían ser la base y la meta de las tareas de nuestros días?" (Zambrano, 1996: 245), posiblemente sea en estas aportaciones de la autora en las que se observa ese carácter anti-orteguiano al que se refiere Tejada en su estudio y que han llevado a pensar que la obra de Zambrano es sin duda una respuesta al maestro. En este mismo sentido, es importante lo que apunta Jesús Moreno Sanz en su estudio introductorio, pues Horizonte del liberalismo asienta un inicio en el vaivén de la autora en la concepción "del absolutismo y las impositivas fijaciones de la razón" (Zambrano, 1996: 165). El investigador expone algunos de sus criterios con respecto a la relación intelectual entre Ortega, Zambrano y la posición de la razón en su pensamiento, analizando cómo este afecta a sus postulados políticos:

Ocurre que Z[ambrano] está proponiendo ya desde aquí un cierto alejamiento de Ortega en el mismo instante en que más parece partir de él. [...] Perspectivas que también le llevarán, desde este libro hasta el artículo "Hacia un saber sobre el alma" de 1934 a elaborar su propuesta de un saber del alma correlativa y profundizadora de sus teorías de la vida y del espíritu [...] En forma que tenemos, entonces, en H[orizonte] del L[iberlismo] los presupuestos mismos de su alejamiento de Ortega y búsqueda -desde la propia razón vital- de "otra razón". Lo que, a su vez, tiene consecuencias políticas decisivas (Moreno Sanz, 1996: 166).

A lo largo del capítulo hemos hecho mención a la categoría de texto programático de ambos escritos. Hemos hecho referencia a que España se convierte -como dice Gabriel Celaya- en el instrumento de trabajo de los autores, que asumen el liberalismo y la regeneración del país como piedras angulares de sus aportaciones. No obstante, sin duda, las reflexiones de ambos autores conducen por senderos muy diversos. Por un lado, de la conferencia de Ortega se desprende una fuerte influencia patriótica, apela a la necesidad de la "nacionalización" y se acoge en numerosas ocasiones a la reflexión sobre la nación española, como parte necesaria para entender el problema que atraviesa el país y, por lo tanto, pieza clave para su reforma. Así, Ortega asume que la Historia de los países es una historia condicionada por la histo- 
ria de las vitalidades nacionales, frente a la concepción generalizada de relacionarla con la historia de las batallas o los jefes de Gobierno. Así las cosas, en el proyecto político que presenta en el marco de la Liga, Ortega busca dedicarse a la reconstrucción de la vitalidad nacional frente al régimen anterior, ya caduco, dirigido en exclusiva a preservar el orden público. Además, en Ortega el liberalismo aparece como la idea sobre la que se sustenta la Nueva política que promulga, y apela a un "liberalismo radical", concepto al que nos referiremos más adelante.

Sin embargo, María Zambrano hace en su obra un repaso por las consecuencias que ha tenido el liberalismo y formula dos líneas de pensamiento, como dice Jesús Moreno Sanz, "la razón cívica" y "la razón poética", que ponen de manifiesto esa vocación integradora y de unidad que se ha comentado y que sintetizan esa voluntad de la autora, ya comentada, de integrar en la reflexión política y filosófica los sentimientos, el amor y las pasiones. En palabras de Moreno Sanz, la intención de Horizonte del liberalismo podría resumirse en contestar a la cuestión de "si es posible un (nuevo) liberalismo que aúne la solución de la necesidad económica con la libertad de la cultura". La aproximación de la autora en esta obra está teñida de un componente social más intenso que en Ortega y expone una valoración del liberalismo mucho más crítica que el maestro para poder formular ese "nuevo liberalismo". Además, no se trata, como en el caso de Vieja y Nueva Política, de la presentación pública de un proyecto político con una institución que la respalde, sino una obra de carácter menos formal en su propósito. En palabras de Moreno Sanz:

Aunque Zambrano, y hasta 1933, seguirá muy vinculada a las concretas postulaciones políticas de Ortega, sin embargo sus concepciones del liberalismo, de la democracia, del capitalismo, y, en general, de los problemas sociales y económicos, serán muy otras; y mostrando progresivamente una mayor apertura a los más radicales postulados y compromisos de la "izquierda" (Zambrano, 1996: 166).

Como enunciábamos, la principal aportación de Ortega en este discurso es la presentación de un proyecto político innovador, la Nueva política, que va más allá de las cuestiones partidistas y que pretende recuperar una políti- 
ca basada en las grandes ideas, al margen de organizaciones concretas. El escritor aclara desde un primer momento que más allá de la reflexión, la política es acción. Lo dice así:

La política es tanto como obra de pensamiento obra de voluntad; no basta con que unas ideas pasen galopando por unas cabezas; es menester que socialmente se realicen, y para ello que se pongan resueltamente a su servicio las energías más decididas de anchos grupos sociales (Ortega y Gasset, 2004: 711).

Es por ello que Ortega, a través y junto a la Liga, se presenta como los impulsores de esa Nueva política, que no puede hallarse solo en conferencias. Así, esa Nueva política que proponen tiene que ampliar sus actividades, más allá de la electoral y parlamentaria e "incluya en sí todas las formas, principios e instintos de socialización". Para esta Nueva política lo más importante es el fomento de la vitalidad española, pues considera que España no es el Estado ni la política ni la corrupción, el fracaso de la Restauración y la situación en que se hallan es producto de que "la raza, la sustancia nacional" están moribundas. Se explica así:

[...] Quien está enferma, casi moribunda, es la raza, la sustancia nacional, y, por lo tanto, la política no es la solución suficiente del problema nacional porque es éste un problema histórico [...] Por tanto, esta nueva política tiene que tener conciencia de sí misma [...] tiene que ser toda una actitud histórica. Ésta es una diferencia esencial (2004: 717).

La nación, por lo tanto, es clave para comprender el proyecto político orteguiano, que está teñido de un fuerte sentido nacional y patriótico, con alusiones constantes a la raza y la vitalidad. España es, ante todo, vitalidad nacional, por encima del sistema político. Cree en una política para la nación y no al revés, algo que le lleva a reafirmarse en su teoría de una política al servicio de la vialidad nacional que conduzcan a los españoles a una "enérgica existencia".

A estos valores ya explorados, Ortega añade el componente del liberalismo como esencial para esa Nueva política. La Vieja, desde su perspectiva, o por lo menos el régimen político de Cánovas, ha impedido el surgimiento de un Partido Liberal verdadero. El Partido Liberal Conservador de Cánovas es 
un "liberalismo domesticado" a los ojos de Ortega. Aunque el escritor apunta su deseo de proclamarse como un grupo liberal, lo cierto es que lo desestima pues considera que en un contexto donde bajo el nombre del liberalismo se ofrecen tan simples opciones políticas, este concepto se ha convertido en un significante vacío, que poco podría decir de sus intenciones políticas. En este sentido, Ortega considera que la Liga se guía por un espíritu radical, radicalmente liberal: "Por consiguiente, yo necesitaría mucho tiempo para explicar en qué sentido nosotros deseamos ser radicales, es decir, extremadamente liberales, mucho más liberales que cuantos partidos tienen hoy representación en el Parlamento", explica Ortega en torno a su proyecto.

Tal y como apunta el profesor Zamora en su biografía de Ortega y Gasset, el filósofo entiende el liberalismo como "aquella emoción radical, vivaz siempre en la historia, que tiende a excluir del Estado toda influencia que no sea meramente humana, y espera siempre, $\mathrm{y}$ en todo orden, de nuevas formas sociales, mayor bien que de las pretéritas y heredadas", siguiendo la síntesis del autor, el liberalismo es para Ortega humanismo y progreso (Zamora, 2002: 135). En esta concepción acoge valores del socialismo, que le llevan, años antes, como hemos visto, a proclamar a Pablo Iglesias como uno de los políticos imprescindibles de España. Sin embargo, el ideario socialista tampoco es suficiente para las pretensiones de Ortega, por su falta de conciencia nacional, su discrepancia respecto a la revolución, además de su rechazo al marxismo o la cuestión republicana como fundamentales (Zamora, 2002). Es por ello que, a pesar de tener la Liga cierta afinidad con el PSOE, esta nunca se materializó, dado el componente monárquico de la agrupación de Ortega y su afinidad con el Partido Reformista, cada vez más en sintonía con el Liberal, como hemos puesto de manifiesto. Sin embargo, como subraya Zamora, lo cierto es que Ortega nunca fue combativo contra el PSOE y admiraba del socialismo su racionalidad (2002: 138).

En el caso de María Zambrano su intención es abordar las complejidades y las contradicciones que el liberalismo, como sistema de pensamiento imperante, presenta, para poder así formular uno nuevo que sea capaz de superar las limitaciones que la autora percibe. Por lo tanto, abraza el liberalismo como la fórmula precisa para una regeneración política, pero no sin antes hacer una revisión y una reformulación exhaustiva. Si para Ortega la salida 
es una Nueva Política, para Zambrano es un Nuevo Liberalismo, que responde a las tendencias europeas y al influjo que tuvo en la autora el socialismo humanista de Fernando de los Ríos, al que nos referiremos en el estudio. Tal y como expone Jesús Moreno Sanz:

Nuevo liberalismo que resuelva las múltiples contradicciones del "viejo" y, sobre todo, las existentes entre cultura y economía, y libertad e igualdad; todo ello, con una renuncia explícita a la "economía liberal" y un esperanzado pronunciamiento final sobre el amor que podría volver a "recrear el mundo" (Moreno Sanz, 1996: 164)

Zambrano inicia su obra sembrando la semilla que guía todo su estudio: la contradicción. La contradicción de la vida, la contradicción del hombre, que "en el hecho mismo de su existencia ya tiene la duda, el problema, el poder ser $\mathrm{y}$, por tanto, no ser" (Zambrano, 1996: 231) y la contradicción de las ideas, que albergan siempre contrarios. Abraza esa concepción de que nada es posible sin la existencia del contrario: la ortodoxia no es factible sin heterodoxia, por ejemplo. Ello nos recuerda varios artículos publicados por la autora años antes, en los que nos detendremos en el capítulo siguiente, donde afirma que, sin la resistencia política hallada bajo el régimen militar de Primo de Rivera, nunca hubiera sido posible la formulación de los pensamientos de las asociaciones universitarias del momento. En su opuesto basó parte de su existencia. Todo tiene explicación y sentido gracias a su contrario. Y esto es lo que la autora considera y denomina "el drama inicial del liberalismo". El liberalismo, sistema de pensamiento que sitúa la liberad en el vértice de sus reflexiones, encuentra en ella la primera gran contradicción: "que para tener libertad, haya que no tenerla". Este es el punto de partida sobre el que asienta Zambrano su teoría, que medita acerca de la relación entre el liberalismo y la ética, el liberalismo y la religión, el liberalismo y el problema social y que culminará en la formulación de ese Nuevo liberalismo al que nos referimos.

Para la autora el pecado original del liberalismo ha sido el intento de crear un universo de pensamiento, una moral, tan pura y racional que ha sido imposible aplicarla al común de las personas. En este sentido, ha nacido como una idea restringida, esencialmente aristocrática, que ha situado al individuo y la razón en el centro del mundo, pero que le ha dejado huérfano 
y solo. Así, el liberalismo racionalista, para la autora, ha sido revolucionario en tanto que creador de algo nuevo, pero ha fracasado. El liberalismo racionalista, en palabras de Zambrano, "montó de nuevo la vida; pero fría y pura como un brillante, la montó al aire; y fue la suprema belleza y la suprema inutilidad (Hombre libre, ocioso, aristócrata... pero sin tierra y sin base. La excesiva pureza lo había matado)".

En este mismo sentido, se desprende de la obra una crítica a la razón occidental, ese Occidente tan heredado de Ortega. Zambrano es crítica con el occidentalismo en su orden religioso, ético y político, como expone Moreno Sanz, muy centrada en la crítica a la Ilustración y Kant, gran inspirador de Ortega. La autora, según el investigador, formaría parte de esa "otra Ilustración", que busca "otras posibilidades de la razón y la política que no sean la mera instrumentalización y la dominación" (1996: 176), pues la autora es lo suficientemente crítica con el liberalismo como para afirmar que ese sistema basado en el gran lema de "Libertad, igualdad, fraternidad" ha sacrificado los dos últimos valores en pro del primero, creando un sistema que, aunque libre, solo crea esclavitud. "El liberalismo se asienta sobre la esclavitud y solo sobre ella puede alcanzar su perfección" (1996: 235), ahí observamos una pincelada del tono social que incluye esta obra. Ello no quiere decir que se sitúe en posiciones cercanas al marxismo o al comunismo, pues si el liberalismo considera que ha caído en una "supervaloración del individuo" (1996: 233) estas corrientes las incluye en una supervaloración de la comunidad, que ha olvidado el valor de lo individual, es lo que denomina comunismo ciego. Además, su objetivo es fundar un pensamiento que supere las concepciones que de ese momento existían de liberalismo y comunismo, pues ambos son resultados del "laboratorio racionalista".

Es sabido: el comunismo es el último resultado del movimiento racionalista, racionalizador de la vida, que comenzó con la reforma religiosa y siguió en lo político con la Revolución Francesa; con la rusa llegó a lo social -punto crítico del problema: individuo y sociedad- (Zambrano, 1996: 256).

Además en ambas corrientes de pensamiento observa falta de justicia. Por un lado un liberalismo injusto y, por otro, la dictadura de la organización económica estatal. 
Zambrano asume en su pensamiento un espiritualismo que pone de manifiesto en esta primera obra. Para la autora el liberalismo presenta dos componentes fundamentales: la razón y el individualismo, que analizaremos. Tal y como anunciábamos al inicio del capítulo, esta reflexión sobre el peso del individuo en el universo liberal está muy relacionado con el marco de pensamiento en el que se inserta, en el que el Nuevo Liberalismo ganaba importancia en Europa.

En su esfuerzo por reformar la razón, la autora recurre a la fe, a la espiritualidad y a la necesidad de una moral que vaya más allá de la razón vital orteguiana. El liberalismo, al situar al hombre y lo humano en el centro de sus concepciones ha eliminado "amarras con lo alto", y es precisamente la moral religiosa, entendida en ella como moral espiritual y no tanto adherida a una doctrina, tan inscrita en el ser humano y tan necesaria, lo que convierte a la moral liberal en moral de élites, inalcanzable para gran parte de la sociedad. "En suma dejaba el liberalismo al hombre concreto y real desconexionado de esta vida en todos sus órdenes, a más de haberle desconexionado del Universo y de Dios", explica Moreno Sanz. Ella misma afirma que nos encontramos ante un gravísimo problema moral -no será el único-, aunque sin duda esta idea se refuerza recurriendo a las palabras de la filósofa:

Lo que tenemos que sacrificar de nuestro ser en aras de la ética liberal es, por lo tanto, los instintos, las pasiones, las emociones [...] ¿Qué nos queda, entonces? Nada. Solo nosotros, nosotros solos con nuestra conciencia, con nuestra razón (Zambrano, 1996: 243).

Ese componente espiritual del que observa carece el liberalismo, lo aprecia en el comunismo, aplicado a lo económico. Otra de las críticas que ejerce va en esa dirección, el liberalismo económico y los abusos a los que ha conducido. Para la autora, el liberalismo conlleva un desequilibrio inicial y aporta a su estudio una visión de clase al asegurar que existe un desequilibrio en la disposición de las clases. No obstante, como hemos avanzado, se desliga de ciertas concepciones marxistas y considera el materialismo como una corriente filosófica fuertemente determinista y simple. Incluye:

"Ella es antidinámica, paralizadora; afirma un dogma para hoy y para siempre, un dogma económico que pretende fundar de nuevo la vida" y de 
ello la deduce como una forma política conservadora. Esta crítica al liberalismo como un sistema económico profundamente injusto no se observa en el texto de Ortega, que apela a las masas y en general a la sociedad española como parte del problema de la decadencia de la vida política española. Sin embargo, para Zambrano esas clases, esas masas a las que denomina "masas humanas" son "el espectáculo de la esclavitud [...] sustentadoras de la aristocracia” (1996: 259).

Por lo tanto, su crítica más intensa se dirige en torno a la forma económica que adopta el liberalismo, que impide que lleve a cabo su propia esencia. El liberalismo "por una parte afirmó los derechos del hombre que hoy vemos que para hacerse efectivos necesitan de una nueva forma económica" (Zambrano, 1996: 261), afirma la autora. Y ella misma observa que los postulados liberales que podemos resumir en los citados: libertad, igualdad, fraternidad que nacieron de la Revolución francesa solo tienen sentido en una socialización de la economía. He aquí parte del pensamiento ambiguo o contradictorio de la autora, en definitiva, parte de su propia esencia y del utopismo que desprende en cierto sentido el texto, un carácter que confirma la investigadora Ana Bundgard al considerar Horizonte del liberalismo "una utopía sin precedentes, un texto programático, una manifestación de audacia intelectual y no únicamente un libro de filosofía política" (Bundgaard, 2005: 5) Ese componente de análisis económico o de clase, más cercano al socialismo, se aleja de la visión aristocrática de la sociedad de Ortega, que, recordemos, hace uso en numerosas ocasiones de la distinción entre la élite y la muchedumbre.

Esa contradicción que hemos aclarado en el capítulo, que hilvana toda la obra de Zambrano, se observa de forma evidente en su concepción del liberalismo económico. Un fenómeno que resumimos en la categórica frase de la autora: "Los postulados espirituales del liberalismo no pueden realizarse con la economía liberal" (Zambrano, 1996: 234).

En Zambrano se observa un componente crítico en lo social y lo económico, cierta concepción de clase que asienta la base de su posterior activismo político, marcado por su participación activa por la república, lo que la condenará a un largo exilio. A pesar de que en Horizonte del liberalismo solo se perfilan algunos puntos clave de esa aproximación a posturas de iz- 
quierdas, que desarrollará más intensamente en los años siguientes, su lectura sobre las clases privilegiadas y las masas podría ser uno de ellos. No obstante, en este texto sigue manteniendo la percepción de que el liberalismo que condujo a esa situación a través de una reformulación será la doctrina que les saque de la situación de crisis que percibe en Europa. Es paradójico observar como la regeneración española pasa en Ortega y Zambrano por la construcción de un proyecto liberal y, sin embargo, este se constituya por tan dispares postulados. En el caso Zambrano hay una voluntad de ir más allá del liberalismo social de Ortega.

Si Ortega apela a la necesidad de los intelectuales de participar en ese cambio político, poniendo la cultura al servicio del mismo, Zambrano también incluye en su obra una reflexión sobre la cultura, muy relacionada con su crítica a la moral liberal. La cultura actual, aristocrática, es la que ha conducido a los efectos perversos del liberalismo. Además, se refiere a esa compleja relación entre las masas y las minorías, en términos de Ortega, lo que Zambrano denomina "los de abajo" y "el aristócrata o intelectual". Ellos, que se han enclaustrado en sus reflexiones, tienen que descender a la práctica en pro de esas clases que han sustentado con su esclavitud el sistema liberal. Además, considera que la economía liberal ha mercantilizado el arte, lo ha desprendido de su esencia y lo ha convertido en el máximo sustentador de las contradicciones liberales. Tanto es así que llega a observar una contradicción entre la cultura (cultura liberal) y democracia económica. Además, en su análisis de la cultura recurre al concepto "cultura burguesa", acogiendo conceptos marxistas (Zambrano, 1996: 260).

Es por todo ello que Zambrano encuentra solución a esta crisis, que ella a lo largo de su texto asume que existe y la observa no solo en España sino en Europa, en una reformulación del liberalismo, que pasa fundamentalmente por un cambio en el sistema económico, la introducción de la moral espiritual y la integración del amor como base de la liberad del ser humano. El sistema humanista por excelencia, el liberalismo, ha perdido en su devenir histórico su condición humana para convertirse, en palabras de Zambrano, en liberalismo capitalista y burgués. No obstante, la autora no propone un proyecto concreto, asume a través de su crítica, cuáles serían los valores a 
modificar, aunque sin mucha profundización en los aspectos más determinados de su nuevo liberalismo.

Parte de las ideas que aporta Zambrano en su obra están muy relacionadas con el concepto de socialismo humanista que desarrolla Fernando de los Ríos en su obra El sentido humanista del Socialismo, publicada en 1926. En este ensayo el autor repasa algunas de las ideas esenciales del socialismo, convirtiéndose, en palabras de Jacobo Muñoz, en el estudio introductorio de la obra, en uno de los teóricos más brillantes del siglo XX del socialismo que "busca el progreso, desde la libertad, hacia un Estado social" (De los Ríos, 2006: 15). Coinciden, Zambrano y De los Ríos, en su reflexión sobre la libertad y el individuo. Si la autora, hemos comentado, ponía de manifiesto la falacia de la libertad liberal, Fernando de los Ríos habla de la relación entre la libertad y el bien común: "Es decir, que es en el deber donde halla su fundamento la libertad; y tan evidente es asimismo que el bien común es la idea que preside la concepción de los propios derechos individuales" (De los Ríos, 2006: 97). Al igual que Zambrano, que incluye entre las páginas de Horizonte del liberalismo un alegato en defensa de la fe y la espiritualidad y no así de instituciones a su servicio, Fernando de los Ríos, reflexiona en torno a la libertad y uno de sus principales enemigos: la Iglesia católica, que considera cuenta desde hace tiempo con un "impulso marcadamente político y guerrero" (2006: 92).

Al igual que Zambrano, De los Ríos eleva lo político a la categoría de lo humano. Es por ello que a lo largo de su implicación política y su trabajo investigador, renuncia al determinismo con el que observa el marxismo, así como a la necesidad de la revolución. Tal y como explica Jacobo Muñoz respecto a la obra de De los Ríos: "Apela a la subjetividad, al método, y, en definitiva, al imperativo moral [...]. Razón por la que entre sus señas de identidad figuran la soberanía de la conciencia y las ideas normativas de la unidad de lo humano - del hombre y de la Humanidad como fines en sí- y de la libertad, inseparables" (De los Ríos, 2006: 65). En definitiva ambos configuran una suerte de reformismo, cada uno con referencias propias, pero sin duda Zambrano se acoge en varias ocasiones a elementos de De los Ríos.

Quizás por el bagaje de la autora, la formulación de su nuevo liberalismo adquiere especial importancia el reconocimiento de las libertades políticas y 
exige un absoluta libertad de expresión. Además, es curioso que este nuevo proyecto político que propone se lo encarga a "liberales del más auténtico y depurado liberalismo" en una labor parecida a la de Ortega cuando apela al liberalismo radical. En ambos se observa, desde distintos puntos vista, la conciencia de que el liberalismo en España no ha manifestado su proyecto más completo.

En conclusión, Vieja y Nueva Política y Horizonte del liberalismo, obras con un fuerte cariz político, nacen de unas circunstancias excepcionales en nuestro país. Un periodo de frustración nacional muy condicionado por el Desastre del 98 o la cuestión de Marruecos, en el caso de Ortega, que observa en el proceso político mismo de la Restauración el contexto en el que han aflorado todos los males históricos de España. Por su parte, la obra de Zambrano se gesta en un contexto de Dictadura. Es una obra de juventud, un rasgo notable a lo largo del texto por su ingenuidad y su utopismo. Ello no quiere decir que sea una obra simple, es todo un texto programático que pone de manifiesto parte de los grandes problemas a los que se enfrenta la España de 1930.

Vieja y Nueva Política asienta un momento clave en la trayectoria política e intelectual de Ortega y Gasset. Su obra se encuentra mucho más marcada por el sentimiento nacional y la idea de colaborar en la creación de un discurso político propio, que se convirtiera en una opción política, que Horizonte del liberalismo. Como hemos afirmado en reiteradas ocasiones, aunque ambos textos presentan una crítica a las situación política española y plantean una serie de propuestas para su regeneración, en el caso de la conferencia de Ortega es mucho más evidente. El tono, el estilo y cómo está configurado el discurso lo convierte en un texto programático. En el caso de Zambrano así lo observamos, coincidiendo con estudios como el de Jesús Moreno Sanz o la profesora Bundgaard. No obstante, su aproximación es de tipo más reflexivo, más filosófico, no proporciona un catálogo de propuestas tampoco Ortega lo hace al uso-. Además, su estudio es todo un análisis del liberalismo desde una perspectiva histórica, de las consecuencias económicas y culturales del mismo, y es de ahí de donde nace su necesidad de formular uno nuevo, por lo que su campo de análisis es mayor y más abstracto que el de Ortega, muy centrado en la problemática española. 
La regeneración del país de ambos pasa por la asunción del liberalismo "verdadero" que se experimenta de forma diferente en cada uno de ellos. La crítica social y económica, la crítica a la moral aristocrática, tan presente en la obra de Zambrano no se observa en el análisis de Ortega, que considera necesaria la introducción de un liberalismo real en relación a la estimulación de la vitalidad nacional. Ciertos matices de análisis de clase que se encuentran en Zambrano no aparecen en la obra de Ortega, aunque aclaramos que ello no quiere decir en ningún caso una adscripción política de Zambrano del tipo comunista, pues descarta el Materialismo histórico como una forma válida de entender la historia y lo observa como una amenaza a la cultura.

En conclusión, la Zambrano de Horizonte del liberalismo es una autora que busca integrar todos los contrarios del liberalismo en un mismo proyecto. Ella misma lo sentencia: "Amplia es la tarea, pues hay que salvarlo todo. Cultura y democracia. Individuo y sociedad. Razón y sentimiento. Economía y libertad". Es una joven que no quiere renunciar por ahora a nada, busca la unidad. El Ortega de Vieja y Nueva Política es un autor menos embebido del espiritualismo de su discípula. Busca una regeneración a través de la razón y encuentra los elementos de crítica a la sociedad no en un análisis escrupuloso del liberalismo, sino en un análisis histórico de la nación. Aunque la obra de Ortega está muy presente en Horizonte del liberalismo, lo cierto es que lo está tanto para el abrazo como para la crítica, motivo por el que fue acogido, como hemos comentado, como un texto profundamente anti-orteguiano. $\mathrm{Su}$ reflexión sobre el liberalismo, muy cercana al socialismo humanista de Fernando de los Ríos, sus constantes referencias a la crítica de Occidente, con una visión social del problema de España la aleja de la visión aristocrática de su maestro. Sin embargo, la historia, la cultura o la razón son tres de los conceptos que Horizonte del liberalismo mantiene en el foco de la regeneración, con una clara influencia de las ideas aportadas por su maestro en Vieja y Nueva Política.

Ambos autores, ambas obras, son imprescindibles para el análisis de la España de las primeras décadas del siglo XX, unas décadas que son el antecedente del devenir de la República y pocos años después de la experiencia de la Guerra. Sin la comprensión de este periodo histórico anterior seríamos incapaces de entender procesos políticos de tal envergadura como los surgi- 
dos en nuestro país a partir de la década de los años 30. Además, el análisis de estas obras, asienta la base sobre la que configurar un estudio de la posición de ambos durante el periodo de la Dictadura de Primo de Rivera, que fueron el germen sobre el que Horizonte del liberalismo se teje y el espacio en el que las ideas expuestas por Ortega en Vieja y Nueva Política se desarrollaron.

\section{LA DICTADURA DE PRIMO DE RIVERA EN EL PENSAMIENTO DE ZAMBRANO Y ORTEGA. INTELECTUALES Y ACCIÓN POLÍTICA}

'La contradicción trágica que toda humana historia proyecta'

Después del recorrido por el pensamiento y la influencia de Ortega en la obra de Zambrano, en concreto por los conceptos asimilados por la autora en su obra Horizonte del Liberalismo, con especial atención a la conferencia del maestro Vieja y Nueva Política, este estudio se propone profundizar en esta relación intelectual que nos ocupa a través de un análisis de la implicación política de Ortega y Gasset y la joven María Zambrano a lo largo del acontecimiento histórico-político que une en tiempo y espacio las obras ya analizadas y que se inserta en el marco de la Restauración: la Dictadura de Primo de Rivera (1923-1930). Una vez asentado parte del pensamiento de Ortega a través de la constitución de la Liga, conviene indagar en el papel que desarrolló a lo largo del régimen militar y, por supuesto, mantener en el estudio la relación que mantuvo con María Zambrano, imprescindible, también, para entender la actividad política y filosófica de la autora durante esa década. Como anunciábamos en el capítulo introductorio, no puede ser de otra forma que esta parte del análisis se dedique, en los primeros años, a la figura de Ortega, y en el estadio más avanzado del régimen a Zambrano, por una cuestión generacional y de afirmación de su propio pensamiento. Además, sin una especial atención a las actitudes adoptadas por Ortega a partir de la década de los años 20 sería muy difícil entender la reflexión político y filosófica de Zambrano durante estos años y que sirvieron de forma excepcional para la elaboración de Horizonte del liberalismo. Todo ello permite al lector 
profundizar en mayor medida en la relación intelectual de ambos, ahondando en las diferencias que presentan ambos durante el periodo que aquí abarcamos, desde 1914 hasta 1930.

En primer lugar, aclaramos el uso del término intelectual utilizado en el título del capítulo. La idea de intelectual es aplicable a los pensadores que aquí estudiamos, en tanto que representantes de dos de las generaciones protagonistas de la primera mitad del siglo XX. Por un lado, Ortega y Gasset, que junto a otros compañeros formaron lo que se ha convenido en llamar y a la que nos hemos referido siempre en el estudio bajo el término la Generación del 14. Por otro lado, María Zambrano, cuya trayectoria se muestra fuertemente determinada por los anteriores y que desarrolló su propio estilo en el marco de una nueva generación, que, como apunta Jesús Moreno Sanz, aparece en 1930 "decidida a servir de nuevo aliento y de aire renovador en aquella coyuntura social de España" (1990: 22), refiriéndose a la experiencia de la dictadura de Primo de Rivera (19231930) y a una España en crisis. No obstante, es importante justificar la inclusión del término intelectual en el presente, concepto al que aludiremos de forma repetida en este punto del estudio.

En España, a la estela de otros países como Francia, donde los escritores se dotaron del nombre "intelectuales" a partir del caso Dreyfus, en el año 1898 se levantó el acta de nacimiento de los intelectuales españoles. Los escritores de este contexto, liderados en la esfera literaria por los literatos de la Generación del 98, se reivindican como tal y asumen su papel para intervenir en política, una posición, además, como apunta Santos Juliá, que les permite ser autónomos del Estado. En definitiva, lo que caracteriza a estos nuevos pensadores, y el motivo por el que es conveniente reivindicar este concepto en aplicación a los autores que aquí se tratan, es, además del consenso histórico posterior en considerarlos como tal, la idea de que lo que les diferencia es que "ejercen su oficio de intelectuales invocando su independencia y su valor y en defensa de la verdad y de la libertad (...). Se trata de intervenir en el campo político en nombre de las normas propias de un campo literario que ha conquistado su autonomía" (Juliá, 2015: 62).

No obstante, Ortega mantiene una consideración propia de la labor de los intelectuales en España, algo a lo que se refiere ya en la primera década del 
siglo XX. Según Juan Marichal, haciendo mención a la concepción orteguiana de intelectual, para el filósofo "los intelectuales tienen que educar a España, para que esta exista realmente, para que sea una nación entera", una idea muy en la línea de lo ya expresado en Vieja y Nueva Política con respecto a los intelectuales. Es decir, para el autor resulta esencial la existencia de una clase intelectual elevada para la creación de pueblo, en un contexto donde la nación española, según el autor, atraviesa una crisis de identidad y de existencia, algo que analizaremos a lo largo del capítulo a partir del estudio de sus artículos de análisis político. Además, para Ortega el intelectual debiera estar al servicio del liberalismo. Ortega se expresa así, tal y como rescata Marichal:

Yo invito a los intelectuales para que, superando un falso buen tono que les mantenga apartados de los problemas públicos, se conozcan obligados a renovar la emoción liberal y con ella el liberalismo (Marichal, 1990: 25).

En el capítulo que iniciamos, se propone al lector un repaso por la contribución política de estos intelectuales en la España del inicio del siglo XX hasta la década de los años 30, un contexto fuertemente marcado por el golpe de Estado de 1923 del General Primo de Rivera que derivó en una dictadura militar hasta su caída en el año 1930. Esta experiencia de la dictadura marcará de forma definitiva el compromiso político de María Zambrano, que desde diversas instituciones se posicionará abiertamente en contra del régimen. Por su parte, Ortega y Gasset mantiene una producción política durante estos años que, aunque menos profusa que en otras épocas, deja entrever su posición reformista ante la dictadura y que ha valido grandes investigaciones posteriores, algunas de ellas que asumen una posición crítica del filósofo ante el nuevo régimen y otros que apelan a cierta asimilación del nuevo orden político por parte del autor.

Ya en 1927 Ortega y Gasset mencionaba que "España es el único país donde los intelectuales se ocupan de la política inmediata", refiriéndose, como apunta Juan Marichal, precisamente, a esa importancia que manifestaron los intelectuales durante la Dictadura de Primo de Rivera y años inmediatamente anteriores. En este sentido, cabe destacar que una tercera parte de las Obras completas de Ortega son textos de carácter político, una produc- 
ción equiparable en extensión al total de sus trabajos filosóficos o al de sus ensayos generales (Marichal, 1990: 33). Con este simple valor estadístico se aclara la dedicación de Ortega al análisis y la propuesta de un proyecto de España a través de su obra. Además, en esa misma línea cabe mencionar que si bien a nivel europeo los intelectuales cobrarán cada vez mayor protagonismo en relación con los asuntos públicos, sobre todo en la época de entreguerras, España se convierte en una suerte de precursora de esta tendencia y, como mencionaba el propio Ortega, los autores españoles influirán en política en una época en la que los países vecinos no desarrollaron tanto esta labor (Marichal, 1990).

Ya en la tarea de desgranar el pensamiento político de Ortega y Gasset en las décadas de dictadura, resulta esencial una revisión de algunos de los artículos políticos publicados en las primeras décadas del siglo XX. En este contexto, revisten considerable importancia las revistas o diarios del momento, entre ellas la publicación semanal Faro (1908- 1909), El Sol (19171939), El Liberal (1879-1939) o Revista de Occidente, iniciada en 1923. En el caso de $E l \mathrm{Sol}$, según Marichal, se trata de "uno de los órganos periodísticos de mayor y más prolongado efecto social modernizador en la España de 1917 a 1930" (1990: 55). Incluso el propio Ortega defiende con rotundidad la utilidad de los periódicos, que considera, desde un tono prescriptivo, que debieran ser arte, una función que, en 1908, considera se está perdiendo: "El periódico no es ciencia, sino arte; arte de emociones sociales. Como en algún modo el político, están encargados de dar a la idea carne de emoción para que se expanda y se haga emotiva" (Ortega y Gasset, 2004: 141). Por lo que a través de estas palabras se deduce la clara vocación política de estos diarios del momento.

A tal efecto se analizan parte de los artículos que consideramos imprescindibles para la comprensión del pensamiento de Ortega y Zambrano, pues ambos autores colaboraron con las revistas mencionadas y dejaron en ellas testigo de su aportación literaria y política; aunque no podemos sino centrarnos en este punto en la labor del maestro, que por edad y madurez, presenta una producción más profusa.

Ya en la década de 1920, en concreto en 1922, aparecen en el diario matutino $\mathrm{El} \mathrm{Sol}$ algunos de los artículos que se han seleccionado para compren- 
der parte del análisis de Ortega y Gasset de la España inmediatamente anterior a la dictadura y posterior. Además, coincide con su vuelta a escena y a la vida pública después de haberse mantenido apartado tras su etapa de director del semanario España. En este momento, el filósofo desarrolla parte de su concepción del "hombre masa", a la que ya alude en Vieja y Nueva Política de forma breve, en una serie de artículos publicados en el diario a partir de febrero del 22 y que se incluyen en su obra España invertebrada (1922). En esta trilogía de artículos que responden al título general de "Patología Nacional", Ortega hace un análisis de la España de ese momento, que considera que padece una crisis que va más allá de lo político, es una crisis cultural. Recordemos, además, que desde hacía unos años en España la alternancia en el Gobierno de dos grandes partidos había perdido peso, y nos encontramos ya ante una política de grandes coaliciones que llevó a que los conservadores se encontraran en el Gobierno, o por lo menos en su mayoría, entre 1919 y 1922 (Villares y Moreno Luzón, 2009: 487). Como hemos analizado, Ortega no sentía especial simpatía hacia la tradición conservadora, en la que tenía escasas esperanzas de hallar la España que soñaba. Es por ello que Ortega desiste de encontrar en la política la causa de la situación española y apunta a la sociedad. En palabras del autor, la crisis en España era una crisis de sociedad, de la sociedad española. El filósofo se expresa así en el primer artículo de esa serie, "Imperio de las masas": "España se arrastra invertebrada, no ya en su política, sino, lo que es más hondo y sustantivo que la política, en la convivencia social misma" (Ortega y Gasset, 2005: 482).

Gran parte del eje de pensamiento de Ortega de este momento gira en torno a la necesidad de las élites -a las que se refiere como minorías o aristocracia en este momento- para configurar una nación sana, una sociedad que sea capaz de dotarse de instituciones que funcionen, manteniendo el tono aristocrático que ya había empleado en 1914. Además, en los textos asume la naturalidad de la constitución de sociedad en torno a minorías y masas. Es por ello que para el autor, la crisis que atraviesa España es en gran medida consecuencia de la no asimilación por parte de las masas de su rol social, lo que deviene en caos: "Así, cuando en una nación la masa se niega a ser masa - esto es, a seguir a la minoría directora-, la nación se deshace, la sociedad se desmembra, y sobreviene el caos social, la invertebración histó- 
rica" (2005: 479). Para el autor, "los mejores" han dejado de dirigir España, siendo una minoría que se ha dejado llevar por las pasiones de la masa, de cuyas opiniones afirma son "siempre inconexas, desacertadas y pueriles", de ahí que sostenga la idea de la invertebración del país y observe que esta se halla en una época de recesión. Algo similar destaca Menéndez Alzamora en su texto, cuando incluye estas palabras atribuidas al filósofo: "Donde no hay una minoría que actúa sobre una masa colectiva, y una masa que sabe aceptar el influjo de una minoría, no hay sociedad o está muy cerca de que no la haya" (Alzamora, 2014: 196).

De este momento también se deduce la concepción de élite de Ortega, que asume que no tiene que relacionarse con una clase o sector concreto, sino con "el hombre excelente", que se halla en todo grupo social. En definitiva, Ortega publica un alegato en defensa de la aristocracia, de la necesidad de la docilidad de las masas, un concepto en el que ahonda en la tercera parte de esta serie en un artículo titulado "Ejemplaridad y docilidad", además se encuentra teñido por un fuerte determinismo histórico en tanto que considera la raíz del problema de España no un problema político, sino puramente social, cultural que ahonda en la esencia histórica de nuestro país.

Esta defensa aristocrática hacia la que avanza será una de las fuentes de discrepancia intelectual y filosófica con María Zambrano, que se aleja progresivamente de su antiguo maestro al configurar un universo de pensamiento diverso y alejado de esa realidad masa minoría.

El 13 de septiembre de 1923 el general Miguel Primo de Rivera y Orbaneja da un golpe de Estado con el beneplácito del rey Alfonso XIII, posición que ha valido numerosos estudios posteriores, y que dejó en suspenso el orden constitucional de 1876 (Villares y Moreno Luzón, 2009: 500). En este contexto, la posición de Ortega frente al régimen ha valido numerosas interpretaciones.

El primer artículo publicado por el filósofo instaurado el nuevo orden, titulado "Sobre la vieja política" y publicado el 27 de noviembre de 1923 en el mencionado diario $\mathrm{El} \mathrm{Sol}$, plantea unas primeras dudas sobre la adhesión o no de Ortega al movimiento. Según el autor el directorio militar supone el fin de la vieja política, algo que el filósofo venía defendiendo como necesario desde antes de 1914, y que se hace evidente con el discurso aquí analiza- 
do, por lo que en cierto sentido ello podría ser revelador. Ortega inicia esta primera pronunciación así:

Alfa y Omega de la faena que se ha impuesto en el Directorio Militar es acabar con la vieja política. El propósito es tan excelente, que no cabe ponerle reparos. Hay que acabar con la vieja política (Ortega y Gasset, 2005: $550)$.

Además, hace alusión a uno de los primeros manifiestos del nuevo régimen, en el que se apela a la sustitución del orden constitucional por un nuevo régimen militar ante el fracaso de los políticos. Ortega, que como hemos comentado ya había desconfiado de la clase política española, lo cierto es que observa en este alegato una clara identificación con la opinión pública española, que considera coincide con esa repulsión a los políticos. Se expresa así: "Nada puede halagar tanto a la gran masa de españoles como que se les diga eso. Que unas cuantas personas, con nombres propios y notorios, son los responsables de sus desventuras" (2005:550), para arremeter contra la "masa de españoles" y de políticos que consintieron que permaneciera un régimen mediocre como el anterior y que ahora agradecen la llegada de los militares. Además, para Ortega esta lectura es del todo simplista, en tanto que, como hemos comentado previamente, la enfermedad de España no es una enfermedad política sino cultural, histórica y de nación. Es un problema, en palabras de Ortega, "de los gobernados". Es llevar a las entrañas adherida la vieja política.

En el artículo publicado, Ortega es recurrente en esa distinción entre la minoría y la masa. Y se refiere a esa minoría compuesta por "los españoles más valiosos, hombres con la conciencia sobremanera limpia". Además, en estas primeras líneas de Ortega tras el golpe se observa una crítica a la demagogia y el populismo de los primeros pasos del Directorio, y, sin embargo, una esperanza o un anhelo de que este nuevo orden tenga en cuenta a esa minoría de la que se siente parte: "Estas minorías no dudan de que los más hondos pensamientos del Directorio sobre los problemas de España se hallan todavía inéditos" (2005: 551). A su vez, se deduce cierto halago por parte del filósofo a la nueva autoridad, al considerar que el antiguo régimen -vieja política- se ha caracterizado por la "flojera de la autoridad", que no se ha permitido nunca violencias. 
No obstante, esta lectura podría parecer algo superficial si no se ahonda en la preocupación y la inquietud que le sugiere este nuevo orden y que pone de manifiesto en el artículo:

Sin embargo yo he de confesar que desde el primer manifiesto lanzado por el general Primo de Rivera mi simpatía y mi adhesión a su obra arrastra una leve inquietud. Cada nuevo decreto, cada nueva nota oficiosa vienen a engrosar este inicial desasosiego. Tanto, en efecto, que la vieja política contra la cual dispara sus rayos el Directorio son un ente muy distinto del que yo quisiera ver aniquilado (Ortega y Gasset, 2005: 553).

Además, se atisba cierta ironía o una suerte de advertencia al nuevo régimen al señalar que un gobierno de estas características es comprensible que acceda al poder en periodos de crisis, pero que si no recobra el orden o la normalidad, el pueblo no será capaz de asumir en el poder político una estructura de la que se siente tan distante.

A pesar de que matiza, como observamos, su adhesión al movimiento, lo cierto es que Ortega no es del todo claro en este primer momento con su postura ante lo acontecido, además de que en un autor tan acostumbrado a verter opiniones políticas en los diarios, sorprende que no hiciera comentario al respecto a través de sus colaboraciones periodísticas hasta dos meses después del golpe. Además, esta espera del autor a pronunciarse al respecto del golpe no se relaciona con la pronta reacción que tuvo ante la llegada de la República, algo que algunos historiadores consideran un hecho revelador, como apunta Tejada (2011: 43). Por otro lado, sorprende que el primer pronunciamiento del filósofo tras el golpe fuera un artículo dirigido al Directorio, "no hacia el pueblo, ni hacia una minoría, sino hacia los más altos representantes de la Dictadura", como suscribe Zamora Bonilla (2002: 237). Aunque también es cierto que Ortega atraviesa en este momento un periodo de crisis con respecto a su actividad política, que ha venido anunciando en artículos anteriores publicados en el diario España, en los que pone de manifiesto la necesidad de que los intelectuales se retiren de la esfera política y se centren en su labor pedagógica, algo a lo que Beatrice Fonck se refiere como la defensa del "imperativo de intelectualidad". Esta parte de la vida y obra del autor es inte- 
resante, en tanto que combina a lo largo de su trayectoria una dicotomía entre su voluntad transformadora, que le lleva incluso a, como se ha comentado, desear la formación de un partido político, hasta, en otros momentos, animar a sus compañeros de la Liga -muchos de ellos parte del Partido Reformista- a que se alejen de la esfera pública y se dediquen a la función pedagógica del intelectual, defendiendo su libertad para "independizarse de cualquier pertenencia política para actuar como minoría estructuradora y educadora de la sociedad" (Fonck, 2010: 8). Testigo de este proceso es el artículo no publicado al que nos referiremos más adelante "Política de estos días", donde Ortega afirma que los intelectuales han venido ocupándose en exceso de la política, con escasos resultados para la nación, aunque se trata de un texto puramente analítico en el que desgrana el presente político de ese momento (1923), símbolo de esa dicotomía que aludimos. Además, ello marca una distancia importante con el Ortega del 14, que a través de la Liga se llamaba intruso en la política pero consideraba esencial su intervención.

Este primer artículo al respecto de la dictadura recién instaurada le vale un conflicto con el diario $\mathrm{El} \mathrm{Sol,} \mathrm{como} \mathrm{subraya} \mathrm{Béatrice} \mathrm{Fonck,} \mathrm{que} \mathrm{en} \mathrm{un}$ editorial posterior se desliga de la concepción de vieja política que el filósofo propone. Tanto es así que el propio Ortega escribe un artículo aclaratorio -no publicado- al respecto del analizado "Sobre la vieja política", titulado "Mi artículo Sobre la Vieja política", en el que explica su anterior "ataque" a las masas como culpables de la mediocridad y del régimen impuesto, en tanto que pasivas e indisciplinadas, y en el que se expresa claro ante su divergencia de parecer con el medio en el que escribe. En palabras de Ortega: "Me era conocido que el diario 'El Sol' no coincidía conmigo ni en la manera de ver la Vieja política ni en el modo de apreciar la actual" (Ortega y Gasset, 2007: 809). Algo que, según la autora, demuestra algunas de las discrepancias ideológicas de Ortega con el medio que podrían ser fuente de "coacciones ideológicas" y que aquí consideramos que pueden aclarar el hecho de que, si bien el filósofo no presenta una posición tajante ante la nueva situación, lo cierto es que desde los círculos en los que se intuía cierta tolerancia hacia el régimen -como es el caso de $E l$ Sol- lo consideran un "removedor de conciencias" y por lo tanto un sujeto poco comprometido con la causa. 
No obstante, como incluye en su estudio Fonck, estas discrepancias con la publicación no presentan algo esencialmente nuevo, sino que desde algunos artículos publicados en 1922, colaboradores del periódico ya habían escrito algunas columnas en las que ponían en duda el criterio filosófico y las opiniones de Ortega, algo que se acentúa a partir de septiembre de 1923, momento en el que el medio publica un artículo anónimo suscribiéndose al régimen, cediendo a las presiones recibidas por la Papelera Española, empresa que mantenía el monopolio del papel en España en este momento y durante buena parte del siglo XX (2010: 13).

En el artículo posterior a "Sobre la Vieja política", es interesante que de forma sutil el filósofo haga mención a esa falta de criterio que impera en la publicación de forma reciente, de la que parece ser conocedor Ortega. Así, aunque agradece la oportunidad de haber podido publicar un artículo contrario a sus postulados, lo cierto es que hace una crítica a la falta de "razones" del medio en su réplica y apela a la necesidad de que exista "fineza de pensamiento" entre sus páginas, algo que podría aludir a esas concesiones que ha hecho el medio ante las presiones de la Papelera. Además, aclara su visión "pesimista" de la sociedad española -en palabras del editorial contrario publicado por $\mathrm{El} \mathrm{Sol}$ - que subyace de su artículo, pues considera que es fruto de la reflexión y no de una valoración simple de la realidad que podría conducir a un optimismo pueril y poco fundamentado.

Según apunta la propia autora, las dudas en torno a la opinión de Ortega ante el orden dictatorial se disipan en cuanto se analiza parte de su producción periodística posterior, sobre todo algunos artículos inéditos que se han incluido en sus Obras completas. A pesar de que aquí ya se ha hecho mención al estado de alerta que se desprende de ese primer artículo publicado por el filósofo tras el golpe de Estado, los sucesivos no dejan de mostrar esa preocupación del autor por saber en lo que degenerará el nuevo régimen. Aunque resulte algo obvio, no podemos dejar de mencionar que nos encontramos en una etapa muy primaria de la dictadura, en la que todavía no se conoce con certeza ante lo que se encuentran, aunque existan muchos indicios del régimen que se desarrollará.

En este sentido, el artículo "Política de estos días", anterior al analizado y que no llegó a publicarse, viene a confirmar esta idea. Ortega está a la espera 
y tiene grandes dudas en torno a la posición de la Monarquía en este sistema y su poder para acabar, en sus términos, con la Vieja política. Cabe mencionar que de un tiempo a esta parte, Ortega ha sido especialmente crítico con la incursión de la Monarquía en política, su responsabilidad en torno al desastre del Annual (1921) y que en parte propició un momento de inestabilidad que favoreció el ascenso de Primo de Rivera.

No obstante, si bien Ortega parece estar alerta, en el artículo mencionado descarta la idea de que el Directorio Militar sea capaz de acabar con la "Vieja política", que tanto le preocupa y que es el foco de la crítica que emana en 1914. Se expresa así: "Los propios generales del Directorio no pueden presentar una hoja de servicio contra la vieja política tan nutrida como el grupo de escritores entre los cuales me hallo incluido" (Ortega y Gasset, 2007: 807). De ello se deduce que Ortega no encuentra motivos para pensar que el régimen militar vaya a sanar a la España que él considera "invertebrada" y que solo a través de una nueva política puede modernizarse y avanzar.

Para completar esta idea que de los artículos de Ortega no publicados se desprende, incluimos, siguiendo el hilo de lo que aporta Fonck, otra de las aportaciones del autor, imprescindible para concluir las muchas reservas con las que acepta este nuevo régimen:

Ahora vemos que no aprobar lo que se hace y se siente en la España de estos días equivale a defender el régimen caído. Por mi parte, no estoy dispuesto a aceptar esa línea mágica que arbitrariamente se quiere trazar con ánimo de imponer a todo prójimo una localización forzosa. La perversidad del antiguo régimen no abona en modo alguno cualquier otro con que se le quiera sustituir. Y las ideas, tópicos, sentimientos que dominan la vida española en estas semanas no me parecen los más adecuados para que se forje una nueva nación saludable (Ortega y Gasset, 2007: 805)

De estas palabras, que el diario El Sol optó por no publicar o censuraron, se pone de manifiesto el malestar que siente Ortega ante estos nuevos acontecimientos y el cambio político que se ha experimentado en España, al no observar en esta nueva tendencia los medios "más adecuados para que se forje una nueva nación saludable". No obstante, se aprecia también una voluntad de no situarse de forma definitiva ni por un lado, de las instituciones de las que se dota ahora España, después del golpe, ni antes, que han fraca- 
sado y que son ineficaces en su labor de regenerar España. Por lo tanto, aunque con un carácter muy escéptico, lo cierto es que Ortega no plantea en estos primeros artículos una crítica severa o una posición firme en torno a lo acontecido. Aunque recordamos que en este momento opera el instrumento de la censura, al que hace mención al inicio de su artículo "Política de estos días" cuando comenta el objetivo de su texto: "Me he preocupado solo de dibujar, con alguna exactitud -dentro de los límites impuestos por la censura- el perfil que a mis ojos ofrece la verdad" (Ortega y Gasset, 2007: 804).

Después de la publicación del artículo que hemos incluido aparecido en El Sol, Ortega no escribe de política hasta siete meses más tarde, preso de la incomodidad de tener que escribir en un medio cuya línea editorial está condicionada a las presiones de los accionistas, así como una decisión de no sometimiento a la censura impuesta. Lo hace en 1924, en forma de una carta al director de $E l$ Sol, recogida en sus Obras completas bajo el título "El intelectual y la política", y que no llegó a publicarse. En él, después de confesar estar dedicándose a la filosofía en perjuicio de la política, reflexiona sobre la imposición que existe sobre los escritores de aportar al terreno de lo político, algo que, en ese punto, considera injusto, y acaba sentenciando que lo mejor es que "cada cual haga lo suyo" (2007: 836).

En este recorrido por el pensamiento orteguiano durante la Dictadura de Primo de Rivera, hemos decidido ahondar en algunos de sus artículos anteriores que faciliten la comprensión del mismo. Por ello, nos detenemos en un artículo publicado el 22 de noviembre de 1927 en El Sol, “¿Reforma del Estado o reforma de la sociedad?”, donde se cuestiona hacia dónde debe dirigirse la reforma de España y que subraya el foco que pone Ortega desde años antes en cuestiones de política sobre la sociedad, más allá de una crítica institucionalista del sistema político. Se expresa así: "Quiere decir esto que, en la realidad histórica, el Estado y cuanto a él se refiere representa un estrato superficial en comparación con lo que pasa en los senos de la sociedad" (Ortega y Gasset, 1927: 1). Además reitera su crítica a los españoles -entre los que se incluye- a quienes considera culpables de la desdichas de España. De este Ortega se deduce una continuación lógica de sus escritos anteriores, en los que ya hace mención a la idea de la masa española como "culpable" de la reali- 
dad en la que habita. No obstante, este texto no incluye una crítica sustancial al régimen ni al sistema político.

Por último, y con ánimo de culminar el relato sobre Ortega en la Dictadura, aunque la producción del autor permitiría un estudio mucho más profundo que aquí, por falta de espacio, no podemos incluir, recalcamos el célebre artículo "El error Berenguer", publicado ya en noviembre de 1930, después de que en enero de ese mismo año la Dictadura de Primo de Rivera cayera en favor de la proclamación por parte de Alfonso XIII del general Berenguer como presidente del gobierno. Este nuevo periodo pasa a la historia bajo el término de Dictablanda y su objetivo principal fue la vuelta a la "normalidad" constitucional de 1874, anterior a la Dictadura.

Esta intención de vuelta a la "normalidad" anterior valdrá una crítica profunda por parte del filósofo en el citado artículo, que acompaña además de un juicio sobre la dictadura anterior, bastante más severo que los aquí expuestos y a la que se refiere como un régimen "salvaje". "(...) He tenido que evocar con un 'mínimum' de evidencia lo que la Dictadura fue. Hoy parece un cuento. Yo necesitaba recordar que no es un cuento, sino que fue un hecho", dice Ortega entre estas líneas, para acabar sentenciando que los actos del régimen fueron "una creciente y monumental injuria, un crimen de lesa patria, de lesa historia, de lesa dignidad pública y privada”. Además, la simpleza del discurso político de este nuevo gobierno ofende al escritor, que considera intolerable la idea de que aparezca un nuevo político con intención de borrar el pasado oscuro de España y retornar a aquel régimen tan poco producente para la historia de España. El objeto de la ira del autor en este artículo es, por encima de políticos, la Monarquía, que ha utilizado las instituciones a su antojo para su propia "comodidad". Así, Ortega, se reivindica como republicano y da lugar a una nueva etapa de su trayectoria, marcada por el advenimiento de la Segunda República varios meses después (abril 1931), la guerra civil, el exilio y su vuelta a España, todo ello acontecimientos que marcarán su futura obra.

En conclusión, podemos afirmar que Ortega no fue del todo complaciente con el nuevo sistema, por lo menos hasta el punto que pudo serlo, en tanto que participaba en un medio fuertemente marcado ideológicamente. Los escritos que aquí se han incluido que no llegaron a ser publicados dan cuenta 
de ello, y ponen de manifiesto a un Ortega que apelaba a la necesidad de una regeneración de España desde una perspectiva alejada de la que integraba el nuevo régimen, en la que no encontraba salida a los problemas nacionales. Esta idea es mucho más evidente en el artículo de 1930, ya finalizada la Dictadura. Además, en este periodo profundiza sobre su teoría alrededor de la posición de las minorías y la masa y hace una crítica intensa a la sociedad española en relación con su cultura política -entre muchos detalles- frente a las opiniones institucionalistas. Por falta de espacio en este ensayo no podemos detenernos en exceso, pero lo cierto es que la figura del escritor y la evolución de su pensamiento político es esencial para entender este periodo oscuro de la historia de España y asimilar las diferencias que presenta con respecto a María Zambrano.

Frente a Ortega y Gasset, que vive desde una posición de renombre el cambio de signo político, ya en una etapa más avanzada y con prestigio intelectual de alcance -ya ha publicado sus primeras obras Meditaciones del Quijote (1914), España invertebrada (1922) y ha dado su célebre conferencia Vieja y Nueva política (1914) - se encuentra la figura de María Zambrano, que nacida en abril de 1904 vive la experiencia de la dictadura recién iniciada su veintena. A pesar de la juventud de Zambrano, lo cierto es que este periodo determina fundamentalmente parte de su pensamiento político y filosófico e inicia una vida marcada por una fuerte militancia y compromiso civil. Tanto es así que con María Zambrano y otros compañeros se inicia lo que hemos denominado en puntos anteriores la Generación del 30, pero que en realidad acoge múltiples nombres: Generación de la Dictadura, Generación neorromántica o Generación de la Libertad, tal y como señala Jesús Moreno Sanz refiriéndose a la denominación de Luis Zulueta, quien describe a este nuevo grupo como una generación política "situada resueltamente en la izquierda y en la extrema izquierda" (Sanz, 1996: 14), una afirmación que permite algunas matizaciones, pues se trató de una generación mayoritariamente progresista, con valores próximos a la izquierda y que fue politizándose con el paso del tiempo, pero que encajar de forma esquemática en "la extrema izquierda" pueda ofrecer al lector una imagen distorsionada de la misma, pues como hemos visto en el análisis de Horizonte del liberalismo Zambrano no duda en desligarse de las concepciones materialistas. No obs- 
tante, en concreto María Zambrano no se sintió nunca parte de ninguna Generación. Lo explica así: "Yo no he pertenecido a ninguna generación -me han puesto en tantas-, no he pertenecido a ningún grupo, aunque en ellos haya estado, en varios (...)" (1996: 20). Además sería un error caer en ese reduccionismo, pues una buena parte de los compañeros de generación acabarían por afiliarse al falangismo y a otros grupos radicales.

En el caso de Zambrano, inicia sus estudios en la Facultad de Filosofía en 1921. La vida universitaria que lleva a cabo esta joven Zambrano se ve marcada por su afiliación a varias de las agrupaciones universitarias más activas del momento y cuya labor acompaña de artículos en la prensa.

Así, en enero de 1927 se constituye la Federación Universitaria Escolar de Madrid, institución que da inicio a la militancia de Zambrano y que fue intensamente activa durante los últimos años de la dictadura de Primo de Rivera. Zambrano, en la entrevista que hemos recogido a lo largo del estudio, recuerda así su etapa en la Federación (FUE):

Vinieron los de la Federación Universitaria Escolar, a quienes dije, entones, que no. Pero yo actué como miembro de la FUE, y activamente el momento de Hoja literaria [publicación literaria anterior en la que participó la autora], no era político; ahora bien, estaba inmerso también en la política, como estaba todo entonces, se quisiera o no, en aquel ambiente de reforma de los modos de expresión, de vivir de otra manera, de que España fuera otra (Moreno Sanz, 1996: 20)

A través de estas palabras, que rescata Jesús Moreno Sanz en su estudio introductorio a la obra de Zambrano Horizonte del liberalismo, que ofreció la autora en una entrevista 1989 a J.C. Marsé, ya se deduce la clara vocación política de esta agrupación universitaria. En este sentido, es interesante observar algunas diferencias que se encuentran entre la forma de expresar su proyecto de España entre Zambrano y Ortega en este momento de la historia de nuestro país, pues a pesar de que gran parte de la trayectoria filosófica de la escritora bebe del sendero marcado por Ortega, lo cierto es que por edad y por la posición en la que les tocó vivir a cada uno de ellos esta nueva situación, su forma de expresar su disconformidad fue muy diferente. Sin duda, en el caso de Zambrano, con un toque más activo en el aspecto militante, desde la esfera universitaria y con menor presión en torno a su orientación. 
En el caso de Ortega, como hemos comentado, ya era un autor conocido cuya opinión influía sistemáticamente en la opinión pública.

Ya en junio de 1928, de forma paralela a la FUE, se funda, claramente influenciada por la ya comentada Liga de la Educación Política de Ortega y Gasset, la Liga de Educación Social, de la que Zambrano sería vocal y en la que colaboraría, determinando sus postulados de forma decisiva. A partir de su fundación, periódicos tales como El liberal, La libertad -ambos de Madrid-, El Norte de Castilla o La libertad-de Badajoz-cedieron un espacio a sus integrantes para la difusión de su pensamiento. En el primer prospecto de esta nueva asociación, surgida de miembros de la FUE, se aclara el objetivo de su nacimiento:

Nos parece asistir a un momento de iniciaciones profundas. Un panorama social surge y se impone, y un cambio de vida adecuado ha de resolver sus problemas, porque ellos se ciñen a la esencia misma de la sociedad. Urge, pues, ser más que espectador y tomar conducta conforme a ideas fijas. El maquinismo creciente trae consigo una potenciación de nuestras posibilidades. Y una clase social, joven y poderosa, el proletariado, se prepara a estructurarse (Moreno Sanz, 1996: 24).

Tal y como sugiere Moreno Sanz en su estudio, gran parte de estas ideas pareciera que fueron aportadas por Zambrano. Pese a que la autora se irá desligando a lo largo de su trayectoria de la tradición marxista, nunca pierde esa lectura de clase que ya se integra en este discurso con su apelación al proletariado como la clase a organizarse ante ese "panorama social" y que se mantiene presente en Horizonte del liberalismo.

De especial importancia en estos primeros años de militancia en la vida de Zambrano son sus colaboraciones en los diarios citados, aquí nos centramos en su participación en El Liberal, en concreto en la sección "Aire libre de la Nueva Generación", donde mantenía una columna bajo el título "Mujeres" -iniciada el 28 de junio de 1928- en la que se resumen gran parte de sus preocupaciones. Siguiendo con la clara intención de este estudio de aportar una voz femenina al ensayo, es importante resaltar que en estas columnas la autora ya se preocupa por la cuestión femenina y la situación de las mujeres en la España del siglo XX, razón por la que nace la columna, que se presenta como una celebración del feminismo incipiente. En la presentación de la 
nueva columna se dice: "Siguiendo con nuestra intención de no teorizar acerca del feminismo - hoy ya un hecho- sino de aceptar -y celebrar- su realidad, abrimos este apartado en nuestra sección" (1928: 3).

Esta relación de Zambrano con lo femenino en este primer punto de su carrera intelectual, en palabras de Moreno Sanz, se podría resumir en: "Una muchacha que, sin ser explícitamente feminista, compendiará en su pensamiento y actuación las esenciales características de las jóvenes 'modernas' y 'emancipadas' que pugnaban por encontrar un lugar renovado para el vivir de las mujeres españolas" (Moreno Sanz, 1996: 21).

A pesar de que el análisis del pensamiento de Zambrano solo en esta primera etapa de juventud es materia suficiente para una investigación mayor, en el presente nos adentramos en la tarea de intentar plasmar de forma sintética algunas de las ideas que de estas columnas se desprenden.

Es significativo el artículo publicado el 5 de julio de 1928, donde rescatamos las palabras de la propia autora, que expone su valoración de una España, que ya sumida en el régimen militar de Primo de Rivera, considera que se constituye como un orden, "una estructura de cosas, que en gran parte es extraño no ya a nuestros principios [la juventud intelectual del momento que conformaba asociaciones como la Liga o la FUE], sino a nuestros supuestos, que como tales nunca hubiesen manifestado al no haber tropezado con una resistencia" (Zambrano, 1928a: 3). Se presenta reveladora esa afirmación de la autora en torno a la necesidad de que exista una resistencia para la difusión de ideas. Es la propia Zambrano quien asume que el momento político excepcional de que son testigos en la juventud tanto a ella como a sus compañeros de militancia le han determinado no solo su actitud, sino su pensamiento, su militancia, su filosofía, y por supuesto, su firme decisión en mantener su palabra como una fuente de revelación contra los criterios impuestos.

Siguiendo con este mismo artículo, la autora hace una defensa de la necesidad de una juventud comprometida, de "sabios" jóvenes -en sus palabrasque más allá de querer "salvar su vida del cambio incesante de la materia", como se refiere a los sabios anteriores, tengan una voluntad de "modificar las cosas, actuar sobre ellas", dejando clara su posición en torno a la intervención del intelectual en política, algo que podría diferir de algunas de las 
posiciones adoptadas por Ortega en los inicios de la década de los años 20 . En esta misma línea, Zambrano continua advirtiendo la necesidad de que "el maestro consagrado y el modesto estudiante se ejerciten en una fina y limpia labor política, que quiere decir no más que acción sobre la cosa pública, acción que supone un amor y un conocimiento". Esta apelación al amor en la labor intelectual, que ella misma sintetiza en la idea de que su ciencia ha de ser "luz intelectual llena de amor" pone de manifiesto uno de los hilos conductores de toda su filosofía, que, como establece Moreno Sanz, es sin duda el descenso al querer que motiva todo conocimiento y saber, y el amor como guía del intelecto. Además su amor a la política se nutre siempre de una elevación de lo político al bien común, alejado de intereses partidistas. Se expresa así: "Y fijar para siempre que hacer política no es estar en éste u otro partido laborando por el bien personal, sino esforzarse con lo mejor de uno mismo para el bien común" y concluye de forma clara su apelación a hacer política desde la reflexión: "Y en este sentido todos -hombres y mujeresestamos obligados a hacer política" (Zambrano, 1928: 3).

No cabe duda de que Zambrano quedará, en algún momento, conviviendo con una cierta frustración ante esa dedicación que esperaba de intelectuales, de hombres y mujeres al fin y al cabo, a la política, a la cosa pública, al bien común. Esa desesperanza se apodera de ella en los años de su exilio (19391984), que, aunque no es menester incluir en nuestro análisis, dan cuenta de esta percepción a la que nos referimos, como en la reflexión que dedica a Gregorio Marañón en Las palabras del regreso (1985), obra de una Zambrano madura, con la experiencia de la dictadura en la que vivió, la guerra y la dictadura posterior que la abocó a la huida. En estas líneas se observa como con los años su optimismo se convierte en un pesar ante una España que le acompaña.

Como sigo estando en España, aunque salí hace tiempo de los avatares políticos, yo no me olvido. Por más que suene otra música. Porque el olvido, al fin y al cabo, es creador: pero la desmemoria, no. La desmemoria lo borra todo. Y eso ¡no! (...) Yo no me vi en una cátedra dando clases de Filosofía, aún con todo lo que la amo, porque no puedo, porque amo la vida. Y la filosofía tiene que estar viva ¿Lo ha estado alguna vez España? ¿O, para estarlo, ha tenido que pasar por la hoguera, ha tenido que quemarse? ¿Y el pensamiento? ¿Cuál ha sido la suerte del pensamiento en España? 
Abstenerse, quedarse quietecito, no meterse en nada y, al hacerlo, rozar la traición y, sobre todo, la tradición (Zambrano, 2009: 94-95).

Ya en 1930, Zambrano está convencida de la necesidad de la implicación política de los que conforman el panorama cultural del momento en España, prueba de ello es una de las cartas que se incluyen en su obra Escritos sobre Ortega, que le envía al maestro donde, como rescata Tejada en su estudio, conmina al antiguo profesor a que se posicione en contra de la Monarquía y a favor de la República, y le reprocha su posición de espectador ante la historia (Tejada, 2011: 36). Once días más tarde, Ortega se declara prorepublicano en su artículo "El error Berenguer" (Ortega y Gasset: 2005a: 760).

No obstante, y retomando el artículo que mencionábamos publicado en $E l$ Liberal, otra de las cuestiones importantes para el pensamiento de la autora y que subyace en el texto, es la idea del amor como guía para la reflexión, un concepto recurrente en la Zambrano de este momento y que se irá completando con una vertiente más espiritualista con el paso de los años. Es más, en el artículo publicado el 28 de junio de 1928, día en el que inicia su columna "Mujeres", se presenta como generación del presente, que guiada por el amor llega a la acción y a la lucha. Además, se introduce como una sección que pretende repasar "todas nuestras preocupaciones, nuestros dilemas, que están ahí ante nosotros, imponiéndose con una evidencia tal vez algo excesiva" (Zambrano, 1928b: 3) poniendo de manifiesto el profundo sentido social y político de sus escritos. Esta influencia en Zambrano de aspectos alejados de la razón será acogida con cierto escepticismo por parte de Ortega, que en ocasiones verá en estas ideas una tentativa de ir más allá de los preceptos de la razón, motor para el pensamiento del maestro.

Por otro lado, es interesante como en sus columnas de esta época -finales de la década de los años 20-, la autora reflexiona sobre la cuestión femenina. En su artículo del 18 de octubre de 1928, Zambrano escribe sobre la modificación del Código penal en torno al adulterio, penada con la pena capital a partir de ese momento tanto en hombres como en mujeres. A pesar que supone poner en igualdad de condiciones a hombres y mujeres, la autora considera esta modificación algo negativo asumiendo que en muchas ocasiones las mujeres no buscan igualarse a los hombres, sino que debiera ser al revés. 
Además, pone de manifiesto que se "ha ganado en lo criminal", mas cuestiones importantes como el trabajo sigue sin organizarse, en concreto se refiere al trabajo de las costureras al que se espera que se dediquen las mujeres, y se pregunta: “¿Será ya la hora de que la mujer de por sí organice y defienda su trabajo y él su ética y su felicidad?" (Zambrano, 1928c: 3). No obstante, y a pesar de que configura una de las piedras angulares de las reflexiones de la autora en los años 20 -y a lo largo de su vida- no nos detendremos en el análisis de su contribución al pensamiento feminista.

Estos primeros textos ya asientan parte del pensamiento de Zambrano, que se materializa en la obra analizada en el capítulo anterior. Sin conocer los artículos que precedieron a la escritura de Horizonte del liberalismo, es complicado trazar un recorrido coherente por el pensamiento de la Zambrano de las primeras décadas del siglo XX. Uno de sus artículos que más ayuda en esta tarea es el publicado en el 26 de julio de 1928, en el que ofrece una reflexión sobre la libertad y el liberalismo. Para Zambrano, que respeta el valor absoluto de la liberad y que entiende que se encuentra en la raíz misma de la democracia, debe concebirse como un valor con límites, impuestos por un orden o "una estructura del mundo", en sus palabras, es decir, debe ser regulada. En un contexto que ella considera de pérdida de derechos, se pregunta sobre "qué es la libertad" y "qué significado puede tener en la vida social [de ese momento] el liberalismo" (Zambrano, 1923: 3). Al igual que su maestro, Ortega, Zambrano confía en el poder regenerador del liberalismo en esta España que no siente propia, en concreto se refiere a la "función social reconstructora del liberalismo" y asegura que una obligación del liberalismo es imponerse en un contexto de cambio y "velar por la civitas", es decir, por los valores democráticos. Además, se dirige especialmente a las masas, haciéndolas partícipe de ese cambio político que ansía, algo que se desliga de la concepción más aristocrática de Ortega y que en 1914 había apelado a las minorías en su discurso Vieja y Nueva Política, para posteriormente seguir desarrollando su concepción de las masas. No obstante, la autora otorga, como el maestro, un peso fundamental a la cultura en este movimiento regenerador.

A la par que su actividad literaria o periodística en estos medios, Zambrano acompañó su actividad política con la organización de eventos, confe- 
rencias, protestas y huelgas en el marco de la LES y la FUE, hasta su disolución en marzo de 1929 (Moreno Sanz, 1996: 28). Además, tal y como señala Moreno Sanz en su estudio ha existido una cierta ignorancia e injusticia histórica al obviar toda su actividad durante estos primeros años, algo que se debe poner de relevancia "por puras razones de veracidad histórica", una actividad que irá aumentando hasta 1939 con su fuerte dedicación a la República y que terminará con un exilio de más de cuarenta años que la mantiene fuera de la escena literaria y filosófica española hasta adentrada la década de los 60. Tal y como subraya Ricardo Tejada en su estudio introductorio a la obra de Zambrano Escritos sobre Ortega, no es hasta 1960 cuando se publica la primera obra de la filósofa en España después de la guerra, cuya recepción en términos generales fue muy complicada, una situación fuertemente determinada, como apunta el autor, por la ausencia en España de la propia Zambrano -todavía en el exilio- y la falta de discípulos que hubiera podido tener en el país (Tejada, 2011: 15).

En conclusión, deducimos una profusa dedicación política por parte de nuestros intelectuales en las tres primeras décadas del siglo XX en España, en concreto aquí representado en las figuras de Ortega y Zambrano, pero que sin duda, acompañaron su largo camino intelectual de una serie de autores y escritores todos ellos esenciales para la comprensión de las nuevas corrientes de pensamiento que surgen en este momento.

En el caso de Ortega, su dedicación a la política sufrirá altibajos, en tanto que se dirime entre la necesidad de que las voces intelectuales sean escuchadas y la necesidad de que estos profesionales se aparten de la práctica política, algo que será también decisivo en los años posteriores que no se incluyen en el estudio, hablamos sobre todo de la década de los 30 y los avatares históricos y políticos que trae consigo en nuestro país. Por su parte, Zambrano mantendrá desde este momento al que dedicamos nuestras líneas hasta el final de su vida un fuerte compromiso social y político, al servicio de diferentes proyectos políticos, sobre todo de carácter prorrepublicano, una circunstancia que bebe de sus primeros años universitarios bajo la dictadura de Primo de Rivera que aquí se ha analizado.

No obstante, no se puede olvidar que Ortega contribuye de forma decisiva a la formulación de un proyecto de España y a la aportación de una con- 
cepción del liberalismo a través de instituciones como la Liga. A pesar de que ambos autores conviven con la experiencia de la Dictadura de Primo de Rivera desde perspectivas y posiciones generacionales muy distintas, sobre todo muy marcada por la juventud de Zambrano, ambos asumen un papel crítico, aunque desde el universo orteguiano sea menos evidente en tanto que estuvo sometido a presiones por parte de los medios en los que colaboraba. Por su parte, Zambrano, como hemos visto, transita durante este periodo por sus primeras experiencias en la militancia civil, alejada de partidos políticos, desde los que considera no siempre se asume la función esencial de la política -el bien común-, pero sí a través de las asociaciones universitarias más activas del momento: la LES y la FUE. Además, bebe necesariamente de conceptos orteguianos pero ello no evita que la joven Zambrano comience a trazar un camino propio, nutrido por la admiración a sus maestros, pero con la convicción de la fuerza de la juventud en la necesaria aportación de un cambio de paradigma político y cultural que observa en España.

\section{CONCLUSIONES}

El trabajo que aquí se presenta se planteaba profundizar en la relación intelectual entre José Ortega y Gasset y María Zambrano, en el contexto político de las primeras décadas del siglo XX. En concreto, hemos tomado como inicio de nuestro estudio 1914, año en el que Ortega presenta la Liga de Educación Política Española con la conferencia Vieja y Nueva Política, sin perjuicio de que se hayan incluido algunos documentos anteriores en el intento de ofrecer al lector una mejor contextualización. Como hito de referencia para finalizar el estudio se ha tomado el año 1930, año de la caída de la Dictadura de Primo de Rivera y de la publicación de Horizonte del liberalismo de María Zambrano.

Así, nuestro principal objetivo, analizar la obra de Zambrano a la luz del pensamiento político orteguiano, materializado en un análisis comparado de las dos obras antes citadas: Vieja y Nueva Política y Horizonte del liberalis$m o$, y de la trayectoria política y filosófica de ambos en el contexto de la 
Dictadura de Primo de Rivera, ha conducido a varias conclusiones que se han puesto de manifiesto a lo largo del estudio.

En primer lugar, Horizonte del liberalismo se trata de una obra de juventud, cargada de elementos ya trabajados por el maestro, pero con un tinte más utópico y místico que el de Ortega. Tanto es así, que Carmen Revilla Guzmán en su estudio "María Zambrano, discípula de Ortega y Gasset" habla de la preocupación que suponía para el maestro la cercanía que presentaba Zambrano a la literatura y la mística, alejada de algunas de sus concepciones más racionalistas que ya están presentes en Vieja y Nueva Política.

A lo largo del estudio hemos señalado que ambas obras son de corte político y programático, más evidente en la obra de Ortega, que se centra en un análisis de España y aporta ideas para su regeneración. En su discurso, Ortega da especial importancia a la vitalidad nacional, que considera esencial para la reforma de España que busca emprender. Además, ambos asumen el liberalismo como la fuente de regeneración necesaria para el país. No obstante, es curioso como en nombre de aquella tradición política ambos autores ofrecen planteamientos diferentes. Zambrano indaga en las contradicciones que el liberalismo ha supuesto en las sociedades occidentales y ejerce una lectura económica y de clase, que Ortega obvia en su texto. Cabe señalar que la obra de Zambrano es el resultado de su trabajo ensayístico durante la Dictadura, muy marcado, como hemos visto, por su afiliación a las organizaciones universitarias del momento, por lo que su aproximación al activismo, su juventud, y la influencia de otros autores como Fernando de los Ríos hace que sea una obra de corte más social y progresista.

Zambrano, además, hereda el racionalismo orteguiano, no obstante, se aleja de él en tanto que ejerce una crítica profunda al liberalismo racionalista y a la moral impuesta por este, que considera se aleja de la realidad humana. Esta presencia de lo humano -en términos de Humanismo- es donde se aprecia la influencia de otras obras como el Sentido humanista del socialismo del ya citado Fernando de los Ríos. Además, Zambrano reflexiona sobre el individuo y el individualismo inherente al liberalismo y a la cuestión de la libertad, algo por lo que Ortega no se preocupa en su conferencia. El filósofo apela a la historia, la Monarquía y la nación como piezas angulares de su discurso. 
Otra de las características esenciales en este momento del análisis y que caracteriza la filosofía de ambos en estas primeras décadas es su relación con la dicotomía entre intelectuales y política. En Zambrano vemos a una autora más combativa, que desde joven como estudiante universitaria se ha implicado en las asociaciones de estudiantes y que apela firmemente en el contexto del régimen militar a la implicación de los intelectuales, no desde sus plumas sabias sino desde una perspectiva más horizontal, cercana también a los estudiantes como ella. Ortega, por su parte, presenta una relación más inestable respecto a esta idea. El Ortega del 14 es un Ortega que llama a la implicación de intelectuales, que hace un canto a lo que él denomina "la minoría", y que, sin embargo, a lo largo de los años irá reformulando su pensamiento, como hemos observado en algunos de sus artículos, hasta llamar a retirarse a los intelectuales de los asuntos públicos. En este sentido, podemos afirmar, que a pesar de la tensión con la que vive Ortega esta relación, lo cierto es que resulta esencial la aportación de los intelectuales de primera mitad del siglo XX, aquí encarnados en las generaciones del 14 y del 30, para la comprensión de los avatares políticos de la España del momento.

La posición del filósofo con respecto a la Dictadura, que se ha analizado en profundidad, ha sido fruto de controversia. Las primeras apariciones del filósofo son a través de artículos en los que se dirige al régimen y en los que podría interpretarse que el autor entiende la Dictadura como un momento de cambio, el que tanto ansiaba desde el 14, sin embargo, en los pocos artículos posteriores matiza la posición y asegura no encontrar en el régimen la Nueva Política que desea. No obstante, no podemos concluir una crítica enfurecida al régimen, sino un Ortega más pasivo con respecto a los asuntos públicos, preso también de la censura.

Por su parte, Zambrano es mucho más contundente y rotunda en su crítica al régimen y su llamamiento es a la juventud. Sus artículos en la sección "Mujeres" que aquí se han analizado dan cuenta de ello. Además, es esencial entender que las posiciones en las que ambos autores se encontraban eran muy diferentes, por una cuestión generacional y de solidez filosófica en el momento del inicio de la Dictadura, 1923. 
Además, resulta imprescindible mencionar a esta altura del estudio la importancia que revisten en este momento los periódicos del momento para la difusión de ideas políticas y filosóficas. Tanto es así que los recursos periodísticos, sobre todo los publicados en El Sol y en El Liberal, han sido clave para desgranar parte del pensamiento de los autores con respecto al régimen.

En conclusión, a través del estudio de los materiales periodísticos, ensayísticos, políticos y sociales de María Zambrano emitidos desde la década de los años 20 hasta los años 30 se encuentran elementos orteguianos, que sirven como inspiración para sus creaciones, ya sea, como se ha explicado, para abrazarlos o rechazarlos. En el intento de desgranar esta relación, ha sido imprescindible, por lo tanto, dedicar atención al análisis de la producción de Ortega durante esos años, para así poder concluir que Horizonte del Liberalismo es, sin duda, una respuesta a Vieja y Nueva Política, que sirve para, frente a esa Nueva Política que se propone, plantear su nuevo proyecto, un Nuevo Liberalismo.

\section{BIBLIOGRAFÍA}

Bungdaard, A. (2005): "El liberalismo espiritual de María Zambrano: Horizonte del liberalismo". Journal of Spanish Cultural Studies. ${ }^{\circ}{ }^{\circ}$ 1. pp 25-41.

De los Ríos, F (2006): El sentido humanista del socialismo. Madrid. Biblioteca Nueva.

Fonck, B. (2010): “Ortega y el poder bajo la dictadura de Primo de Rivera a la luz de los inéditos del tomo VII de las 'Obras completas", Revista de Estudios Orteguianos, $n^{\circ}$ 20, pp. 7-19. Disponible en:

http://www.ortegaygasset.edu/admin/descargas/contenidos/Ortega_\%20y _el_poder_bajo_la_dictadura_de_Primo_de_Rivera.pdf.

[Consulta: 09/08/2018]

Hobhouse, L.T. (1911): Liberalism:

https://socialsciences.mcmaster.ca/econ/ugcm/3113/hobhouse/liberalis m.pdf [Consulta: 09/08/2018] 
Juliá, S, (2015): Historia de las dos Españas. Penguin Radom House. Madrid. Taurus.

Marichal, J (1990): El intelectual y la política. Madrid. Publicaciones de la Residencia de Estudiantes. CSIC.

Menéndez Alzamora, M (2014): La Generación del 14. Intelectuales y acción política. Madrid. Catarata.

Ortega y Gasset, J (1927): “¿Reforma del Estado o reforma de la sociedad?”. El Sol, 22 de noviembre. $n^{\circ} 3214$. pp. 1

Ortega y Gasset, J (2004): Obras completas: Tomo I (1902-1915). Madrid Taurus.

Ortega y Gasset, J (2005): Obras completas: Tomo III (1917-1925). Madrid. Taurus.

Ortega y Gasset, J (2005a): Obras completas: Tomo IV (1926-1931). Madrid. Taurus.

Ortega y Gasset, J (2007): Obras completas: Tomo VII (1917-1925). Madrid. Taurus.

Revilla Guzmám, C (2012): "María Zambrano, discípula de Ortega y Gasset". Aurora. n13. pp. 6-7.

Tejada, R (2011): Escritos sobre Ortega. Madrid. Trotta.

Villares, R. y Moreno Luzón, J, (2009): Restauración y Dictadura. Barcelona. Crítica/Marcial Pons

Zambrano, M (1928b): "Mujeres". El Liberal, 28 de junio, n 17171. pp. 3. Zambrano, M. (1928): "Mujeres". El Liberal, 18 octubre, no 18067. pp. 3.

Zambrano, M. (1928a): “Mujeres”. El Liberal, 5 de julio. no 17177. pp. 3.

Zambrano, M. (1928c): "Mujeres". El Liberal, 26 de julio. no 17195. pp. 3.

Zambrano, M. (1996): Horizonte del liberalismo (Edición y estudio introductorio a cargo de Jesús Moreno Sanz). Madrid. Ediciones Morata.

Zambrano, M. (2009): Las palabras del regreso. Madrid. Cátedra.

Zamora Bonilla, J. (2002): Ortega y Gasset. Barcelona. Plaza y Janés. 